\title{
Photo-Induced Etherification of Less-Strained Cycloketoxime Esters Enabled by C-C Bond Cleavage
}

\section{(Supporting Information)}

Mengning Wang, ${ }^{\dagger}$ Cheng Chen, ${ }^{\ddagger}$ Mengtao Ma,${ }^{\dagger}$ Binlin Zhao, ${ }^{\dagger}, *$ and Zhuangzhi Shi ${ }^{\ddagger}$

tDepartment of Chemistry and Material Science, College of Science, Nanjing Forestry University, Nanjing 210037, China. E-mail: zhaobinlin@njfu.edu.cn

State Key Laboratory of Coordination Chemistry, School of Chemistry and Chemical Engineering, Nanjing University, Nanjing, 210093, China.

1. General Information. ............................................................2

2. Preparation of the Oxime Esters................................................... 3

3. Reaction Set-Up for Irradiation with Blue LEDs...............................3

4. Mechanistic Studies................................................................4

5. Copies of NMR Spectra ........................................................ 


\section{General Information.}

All new compounds were fully characterized. NMR-spectra were recorded on Bruker ARX-400 MHz, ARX-500 MHz or ARX-600 MHz Associated. ${ }^{1} \mathrm{H}$ NMR spectra data were reported as $\delta$ values in $\mathrm{ppm}$ relative to chloroform $\left(\delta\right.$ 7.26) if collected in $\mathrm{CDCl}_{3} \cdot{ }^{13} \mathrm{C}$ NMR spectra data were reported as $\delta$ values in ppm relative to chloroform $\left(\delta\right.$ 77.00). ${ }^{1} \mathrm{H}$ NMR coupling constants were reported in $\mathrm{Hz}$, and multiplicity was indicated as follows: s (singlet); d (doublet); t (triplet); q (quartet); quint (quintet); $\mathrm{m}$ (multiplet); dd (doublet of doublets); ddd (doublet of doublet of doublets); dddd (doublet of doublet of doublet of doublets); dt (doublet of triplets); td (triplet of doublets); ddt (doublet of doublet of triplets); dq (doublet of quartets); app (apparent); br (broad). Coupling constants are reported as a $\mathrm{J}$ value in $\mathrm{Hz}$. Carbon nuclear magnetic resonance spectra $\left({ }^{13} \mathrm{C}\right.$ NMR) are reported as $\delta$ in units of parts per million (ppm) downfield from SiMe4 ( $\delta$ $0.0)$ and relative to the signal of chloroform-d ( $\delta$ 77.00, triplet). Mass spectra were conducted at Micromass Q-Tof instrument (ESI) and Agilent Technologies 5973N (EI). All reactions were carried out in flame-dried reaction vessels with Teflon screw caps under argon. $f a c$ - $\left[\operatorname{Ir}(\mathrm{ppy})_{3}\right]$ was purchased from Acros. Unless otherwise noted, materials obtained from commercial suppliers were used without further purification. 


\section{Preparation of the Oxime Esters}

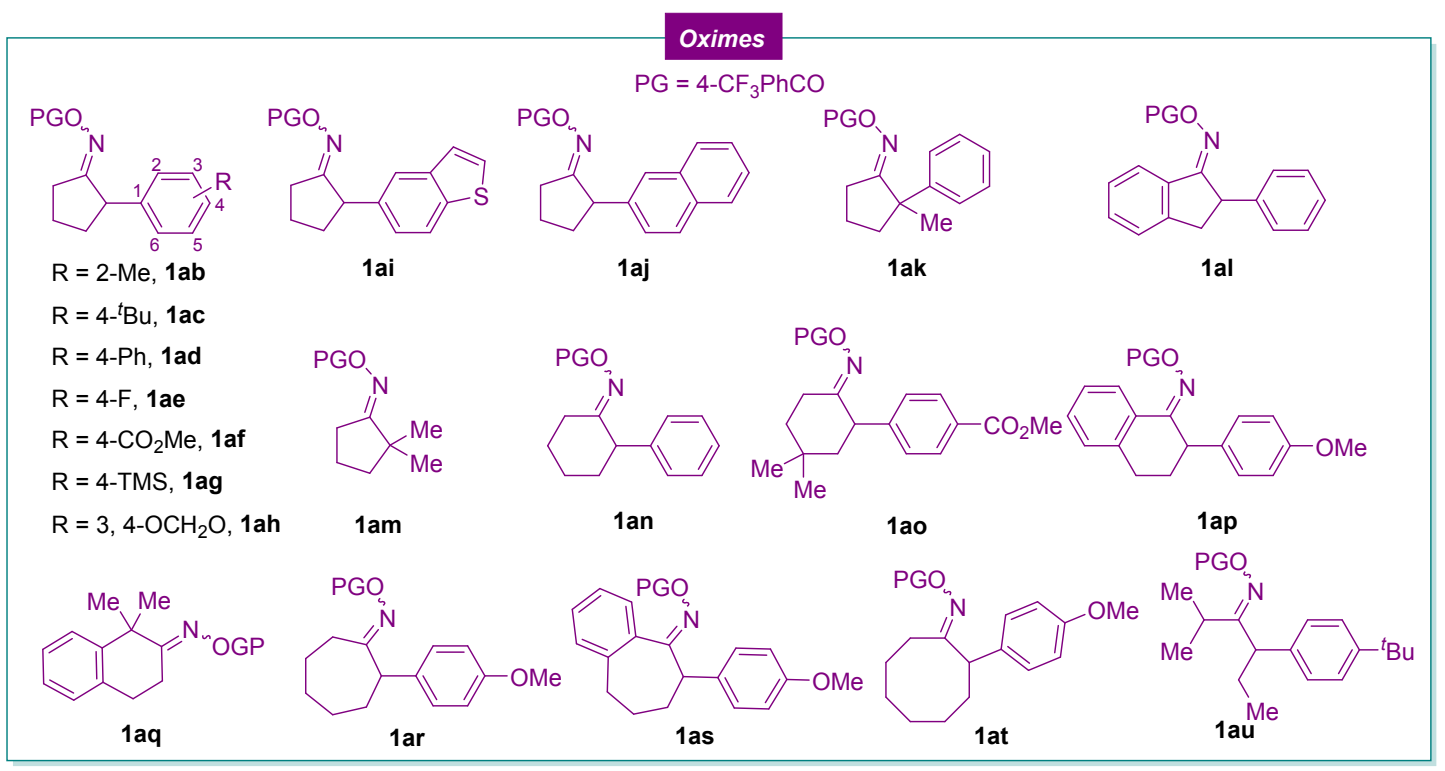

The oximes 1 shown in the above table were synthesized according to our previous work and the spectral data were in accordance with the literatures..$^{1,2}$

\section{Reaction Set-Up for Irradiation with Blue LEDs}

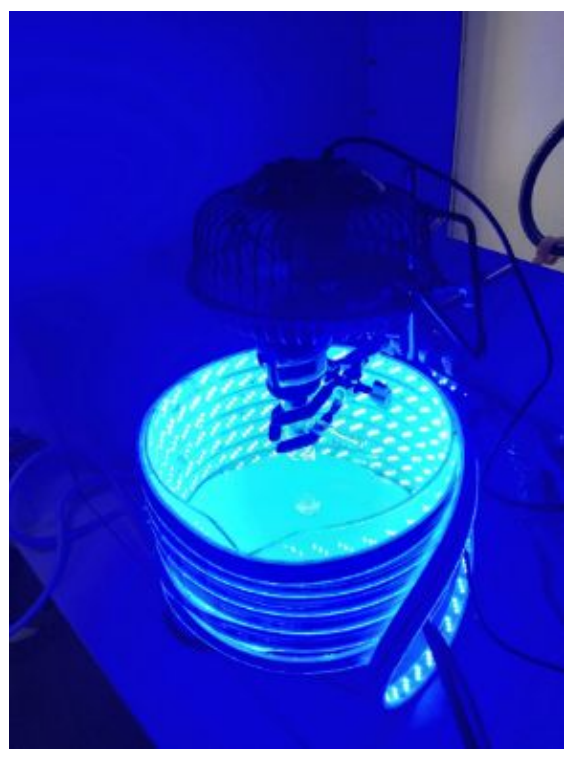

LED strips: $12 \mathrm{~W} / \mathrm{m} * 3 \mathrm{~m}$ was purchased from www. taobao. com.

1 Zhao, B.; Tan, H.; Chen, C.; Jiao, N.; Shi, Z. Photoinduced C-C Bond cleavage and oxidation of cycloketoxime esters. Chin. J. Chem. 2018, 36, 995.

2 Zhao, B.; Chen, C.; Lv, J.; Li, Z.; Shi, Z. Single-electron-transfer (SET)-induced fragmentation-rearrangement sequence of cycloketoxime esters. Org. Chem. Front. 2018, 5, 2719. 


\section{Mechanistic Studies}

\section{a) Radical-trapping experiment}

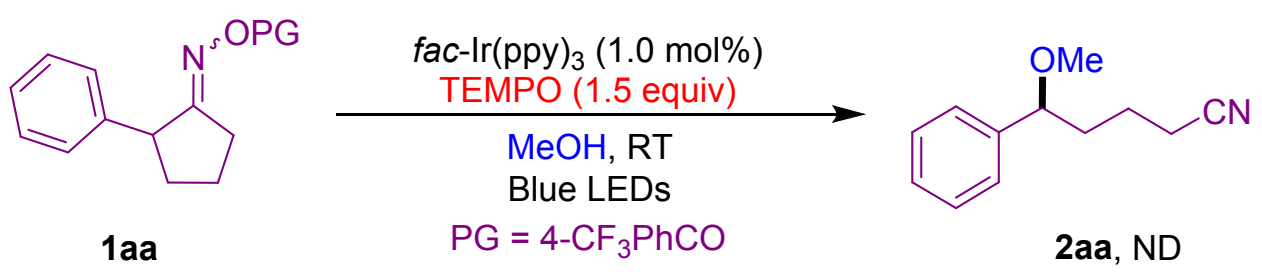

Flame-dried $25 \mathrm{~mL}$ Schlenk tube filled with argon, Ketoxime 1aa $(0.2$ mmol, 1.0 equiv), $f a c-\operatorname{Ir}(\text { ppy })_{3}(0.002 \mathrm{mmol}, 1.0 \mathrm{~mol} \%)$, TEMPO $(0.3$ mmol, 1.5 equiv), absolute alcohol $(2.0 \mathrm{~mL})$ were added under $\mathrm{N}_{2}$. The formed mixture was stirred at room temperature with the irradiation of blue LEDs $(10 \mathrm{~W} / \mathrm{m} * 3 \mathrm{~m})$ for $24 \mathrm{~h}$ as monitored by TLC. The solvent was removed under vaccum directly. The crude product was analyzed by TLC and GC-MS, no desired product $2 \mathbf{a a}$ was detected.
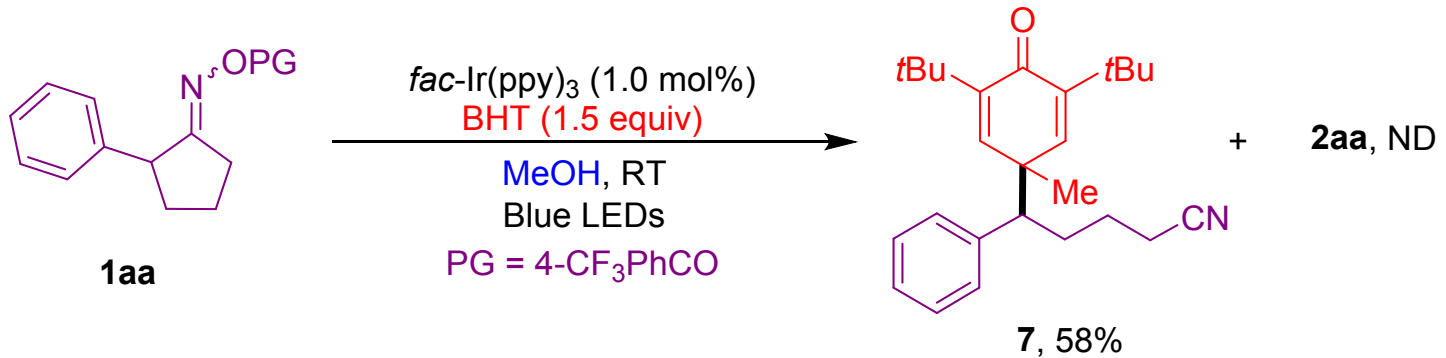

Flame-dried $25 \mathrm{~mL}$ Schlenk tube filled with argon, Ketoxime 1aa $(0.2$ mmol, 1.0 equiv $), f a c-\operatorname{Ir}(\mathrm{ppy})_{3}(0.002 \mathrm{mmol}, 1.0 \mathrm{~mol} \%)$, BHT $(0.3 \mathrm{mmol}$, 1.5 equiv), absolute alcohol $(2.0 \mathrm{~mL})$ were added under $\mathrm{N}_{2}$. The formed mixture was stirred at room temperature with the irradiation of blue LEDs $(10 \mathrm{~W} / \mathrm{m} * 3 \mathrm{~m})$ for $24 \mathrm{~h}$ as monitored by TLC. The solvent was removed under vaccum directly. The crude product was analyzed by TLC and GCMS, no desired product 2aa was detected. And the crude mixture was 
purified by flash column chromatography on silica gel (eluent: PE/EA = $15: 1)$ to afford the radical-trapping aduct 7 as a colorless oil $44.2 \mathrm{mg}$ (58\%): ${ }^{1} \mathrm{H}$ NMR $\left(600 \mathrm{MHz}, \mathrm{CDCl}_{3}\right) \delta 7.29-7.25(\mathrm{~m}, 3 \mathrm{H}), 7.23-7.21(\mathrm{~m}$, 1H), $7.07-7.02(\mathrm{~m}, 2 \mathrm{H}), 6.55(\mathrm{~d}, J=2.9 \mathrm{~Hz}, 1 \mathrm{H}), 6.39(\mathrm{~d}, J=2.9 \mathrm{~Hz}, 1 \mathrm{H})$, $2.70(\mathrm{dd}, J=12.3,3.1 \mathrm{~Hz}, 1 \mathrm{H}), 2.21(\mathrm{td}, J=7.1,1.3 \mathrm{~Hz}, 2 \mathrm{H}), 1.88-1.82$ (m, 1H), $1.74-1.67(\mathrm{~m}, 1 \mathrm{H}), 1.48-1.34(\mathrm{~m}, 2 \mathrm{H}), 1.26(\mathrm{~s}, 9 \mathrm{H}), 1.14(\mathrm{~s}$, 3H), 1.11 (s, 9H).

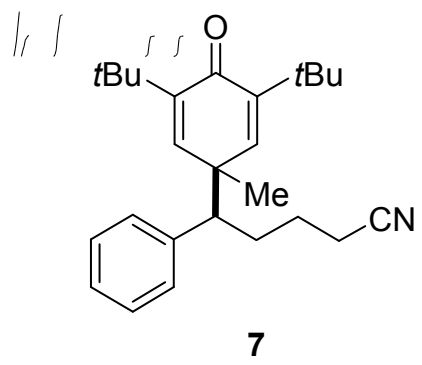

${ }^{1} \mathrm{H}$ NMR (600 MHz, $\mathrm{CDCl}_{3}$ )

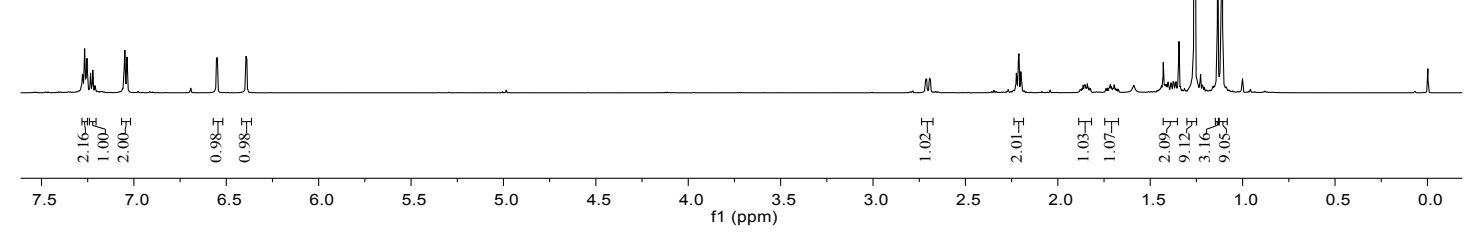

\section{b) Light-on/off experiment}

Flame-dried $25 \mathrm{~mL}$ Schlenk tube filled with argon, Ketoxime 1aa $(0.2$ mmol, 1.0 equiv), $f a c-\operatorname{Ir}(\mathrm{ppy})_{3}(0.002 \mathrm{mmol}, 1.0 \mathrm{~mol} \%)$, absolute alcohol (2.0 mL) were added under $\mathrm{N}_{2}$. The formed mixture was performed using alternating intervals of light and dark. The reaction profile is shown above and the yield of product 2aa was determined by GC-MS 
(Dodecane was used as an internal standard). These results indicated that the reaction was heavily relied on the continuous light irradiation.

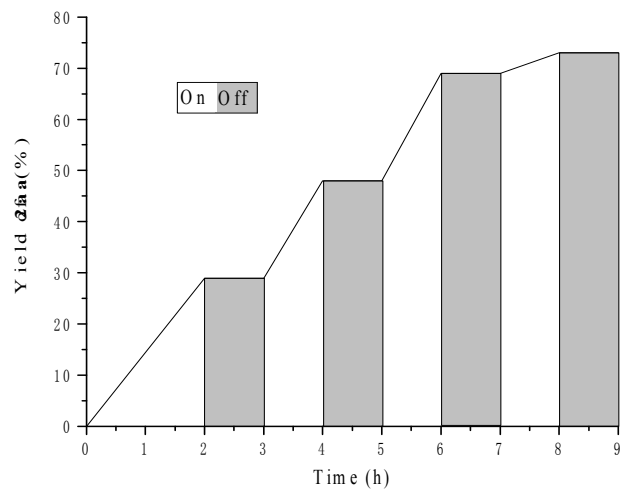




\section{Copies of NMR Spectra}
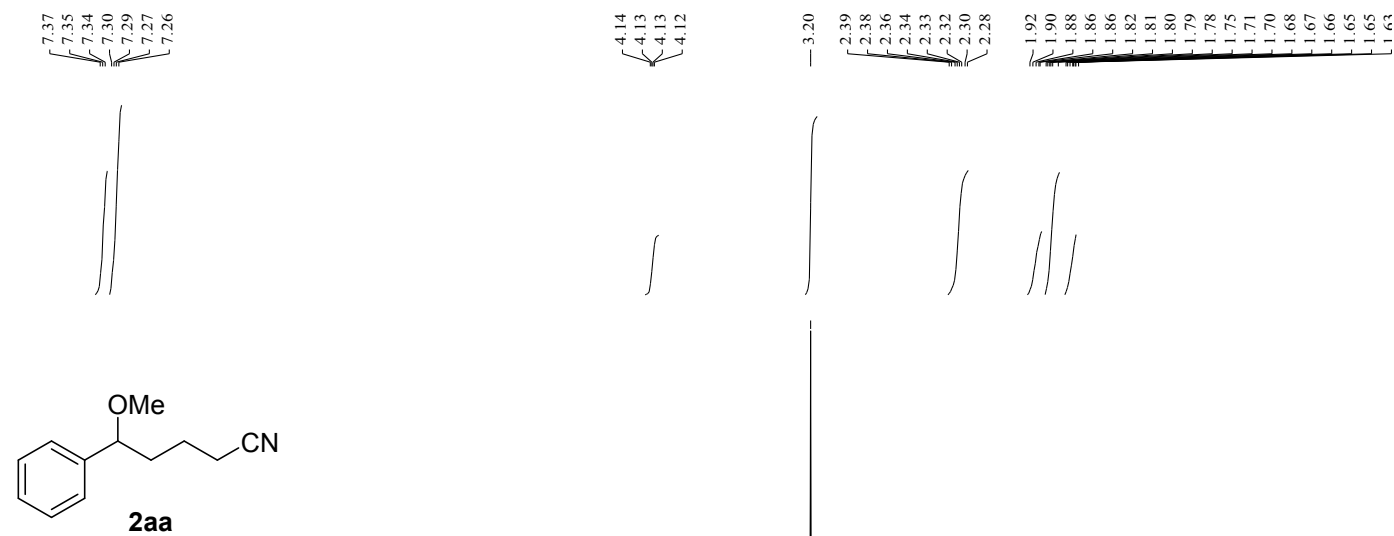

${ }^{1} \mathrm{H}$ NMR $\left(500 \mathrm{MHz}, \mathrm{CDCl}_{3}\right)$
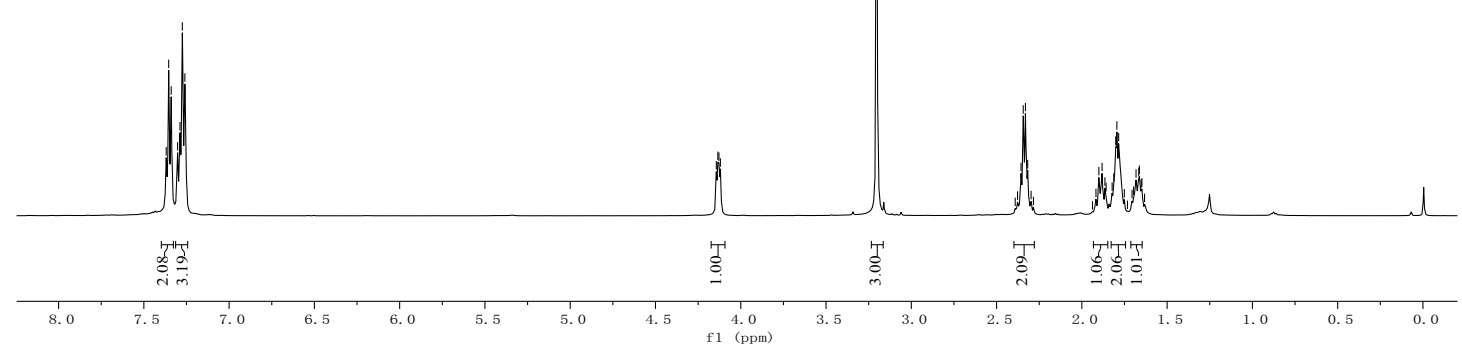

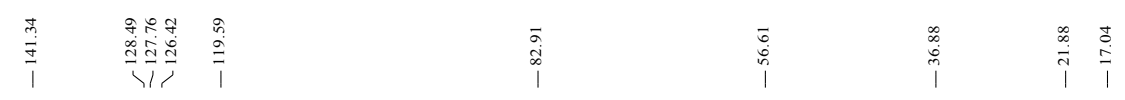

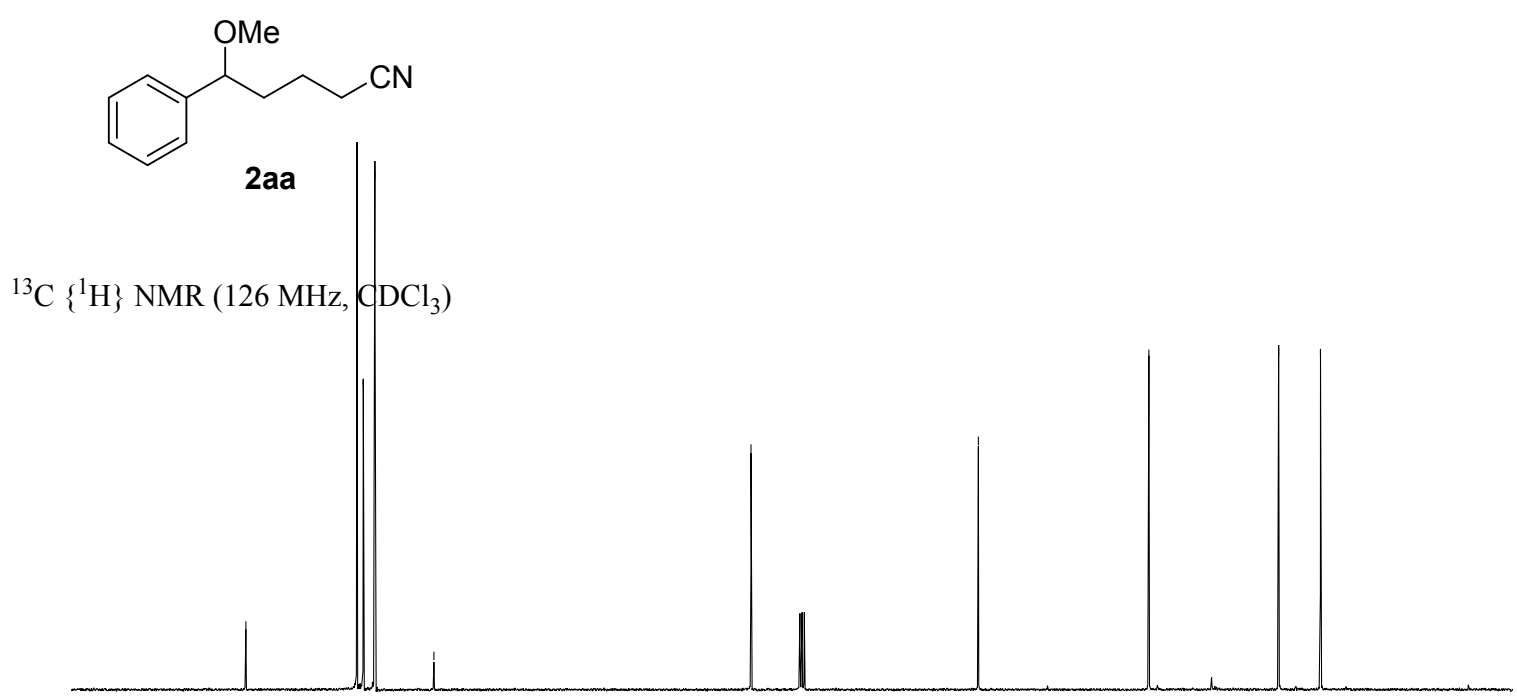


<smiles>CC=CC</smiles><smiles>COC(CCCC#N)c1ccccc1C</smiles>

$2 a b$

${ }^{1} \mathrm{H} \mathrm{NMR} \mathrm{(400} \mathrm{MHz,} \mathrm{CDCl}_{3}$ )

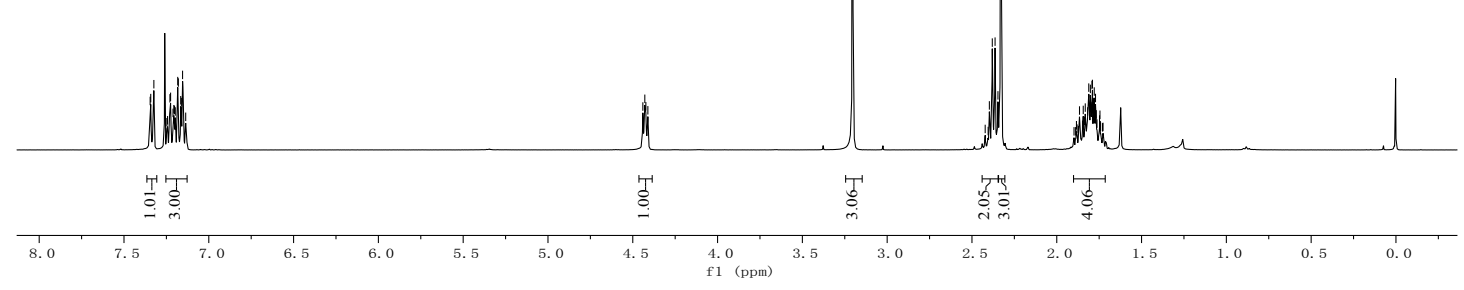

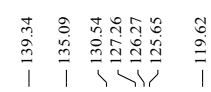<smiles>COC(CCCC#N)c1ccccc1C</smiles>

$2 a b$

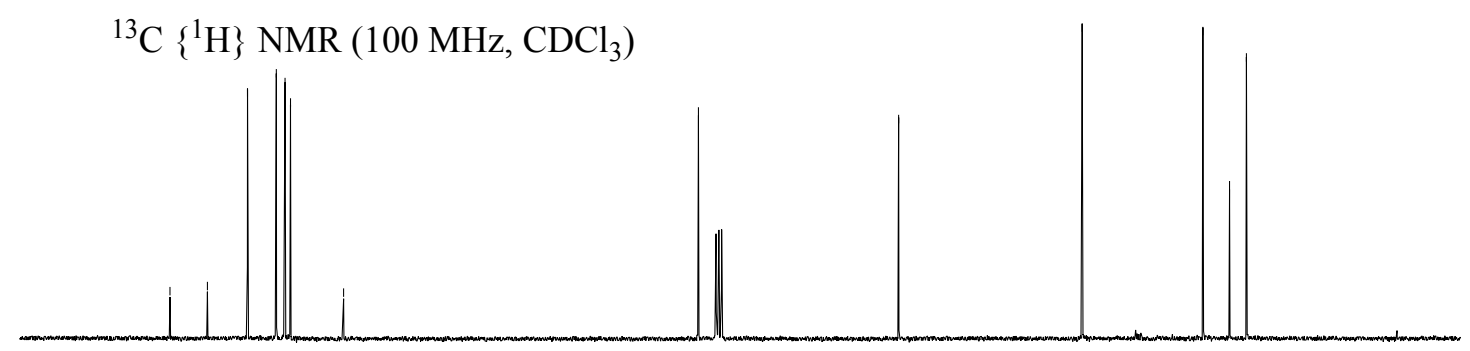



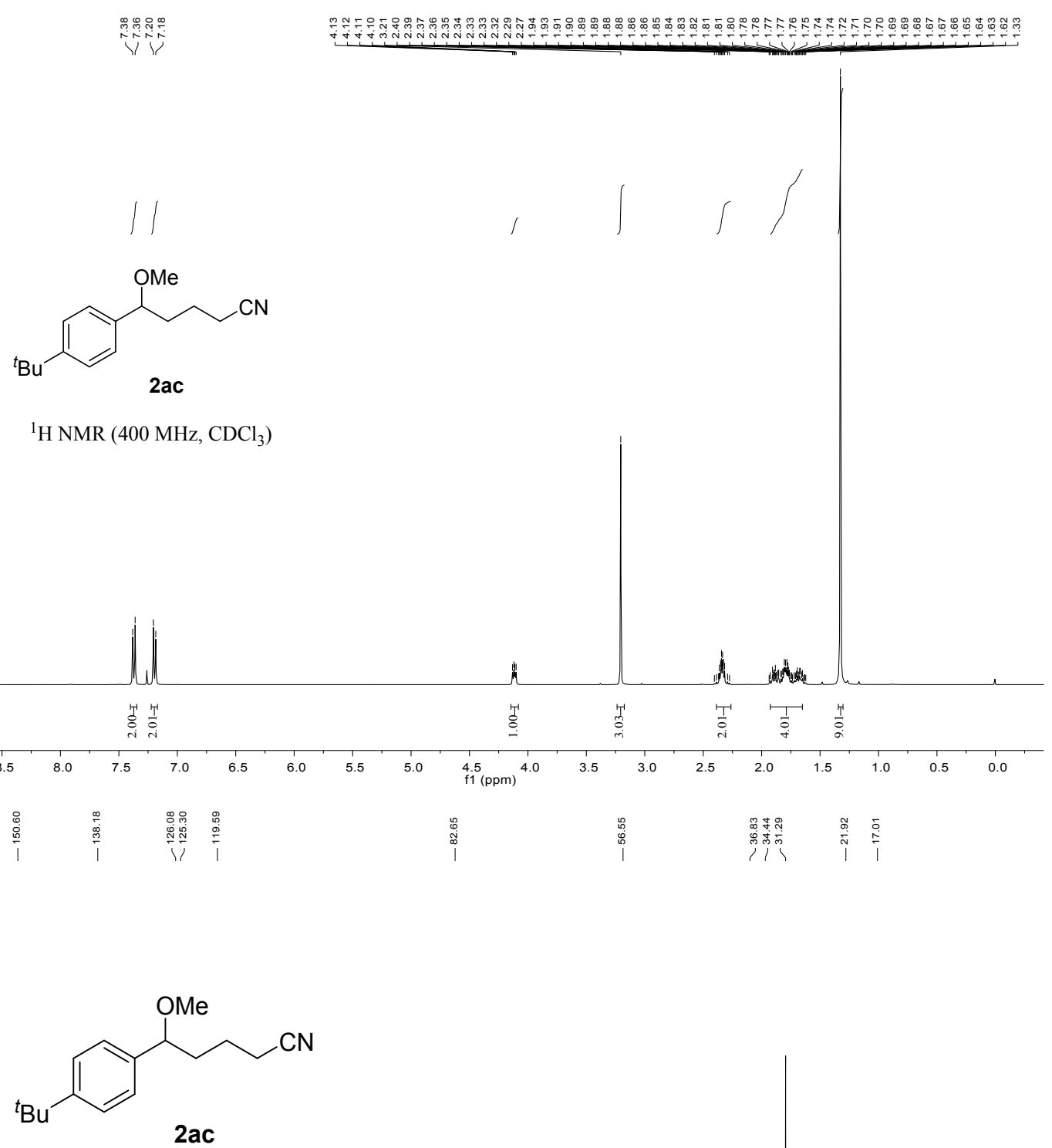

${ }^{13} \mathrm{C}\left\{{ }^{1} \mathrm{H}\right\}$ NMR $\left(100 \mathrm{MHz}, \mathrm{CDCl}_{3}\right)$
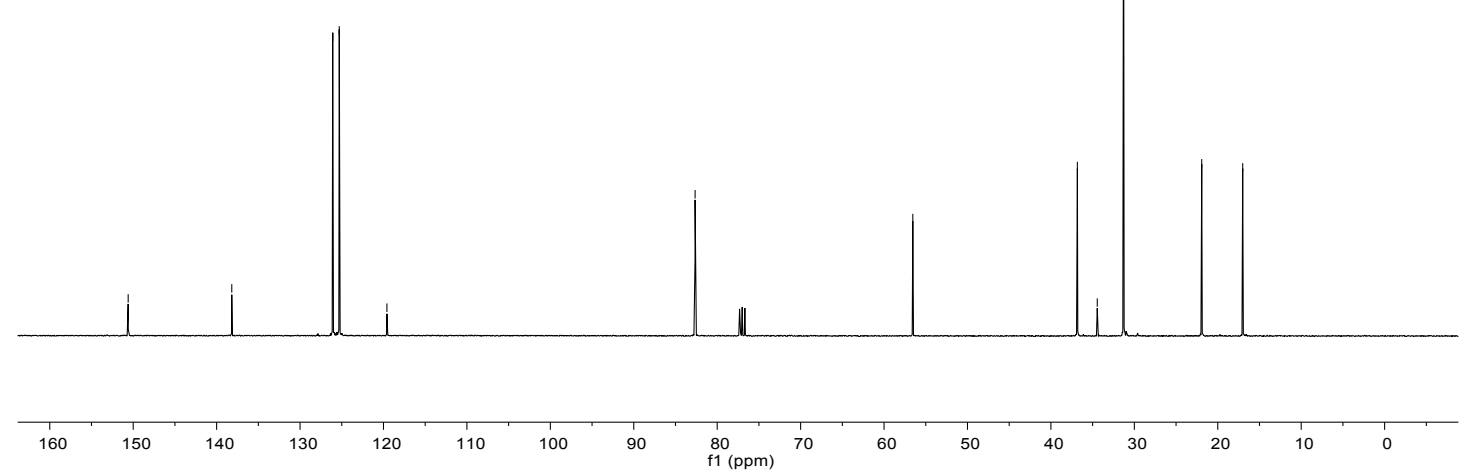


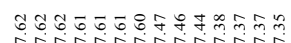

$\iint$

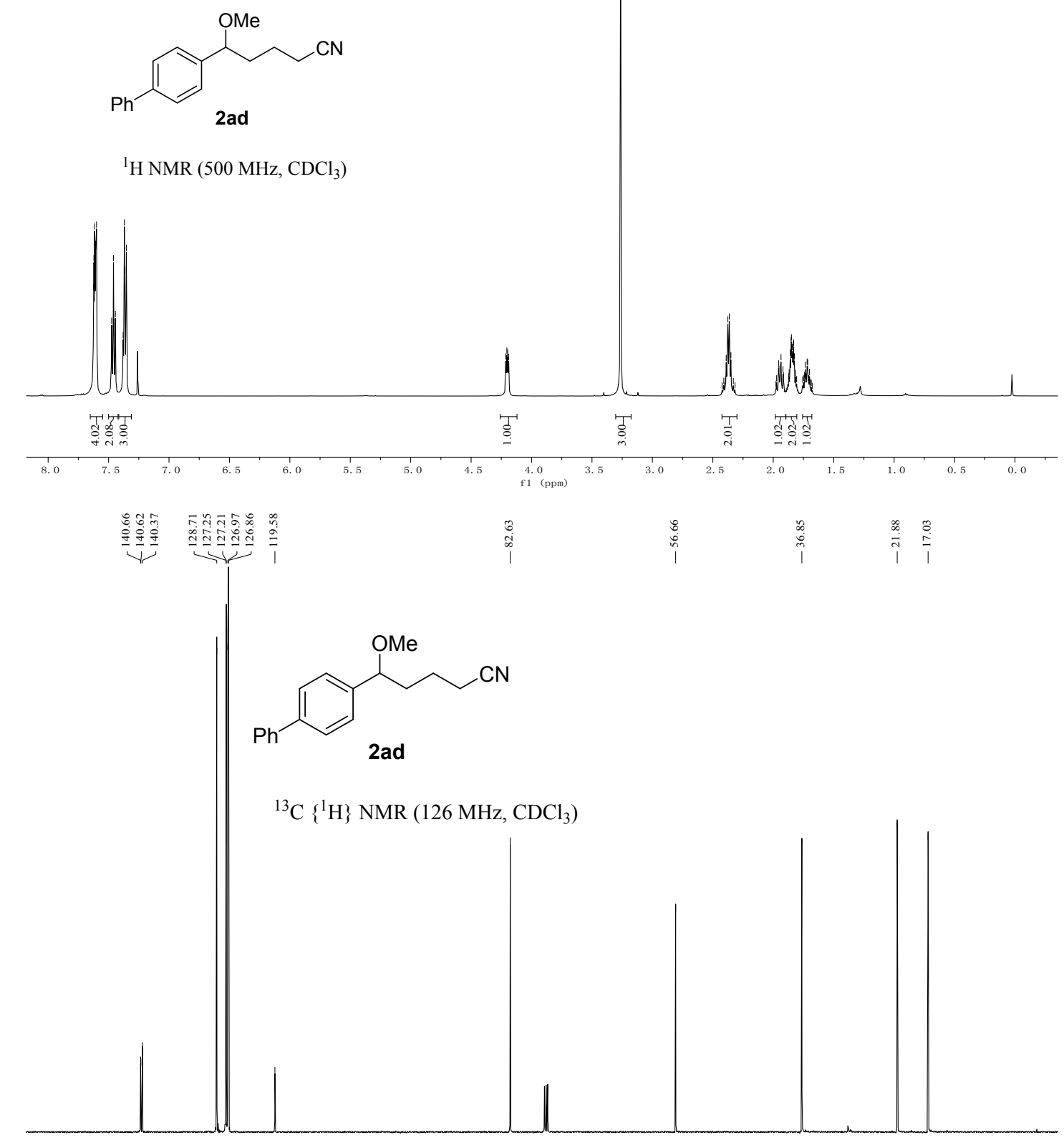

${ }^{1} \mathrm{H}$ NMR $\left(500 \mathrm{MHz}, \mathrm{CDCl}_{3}\right)$
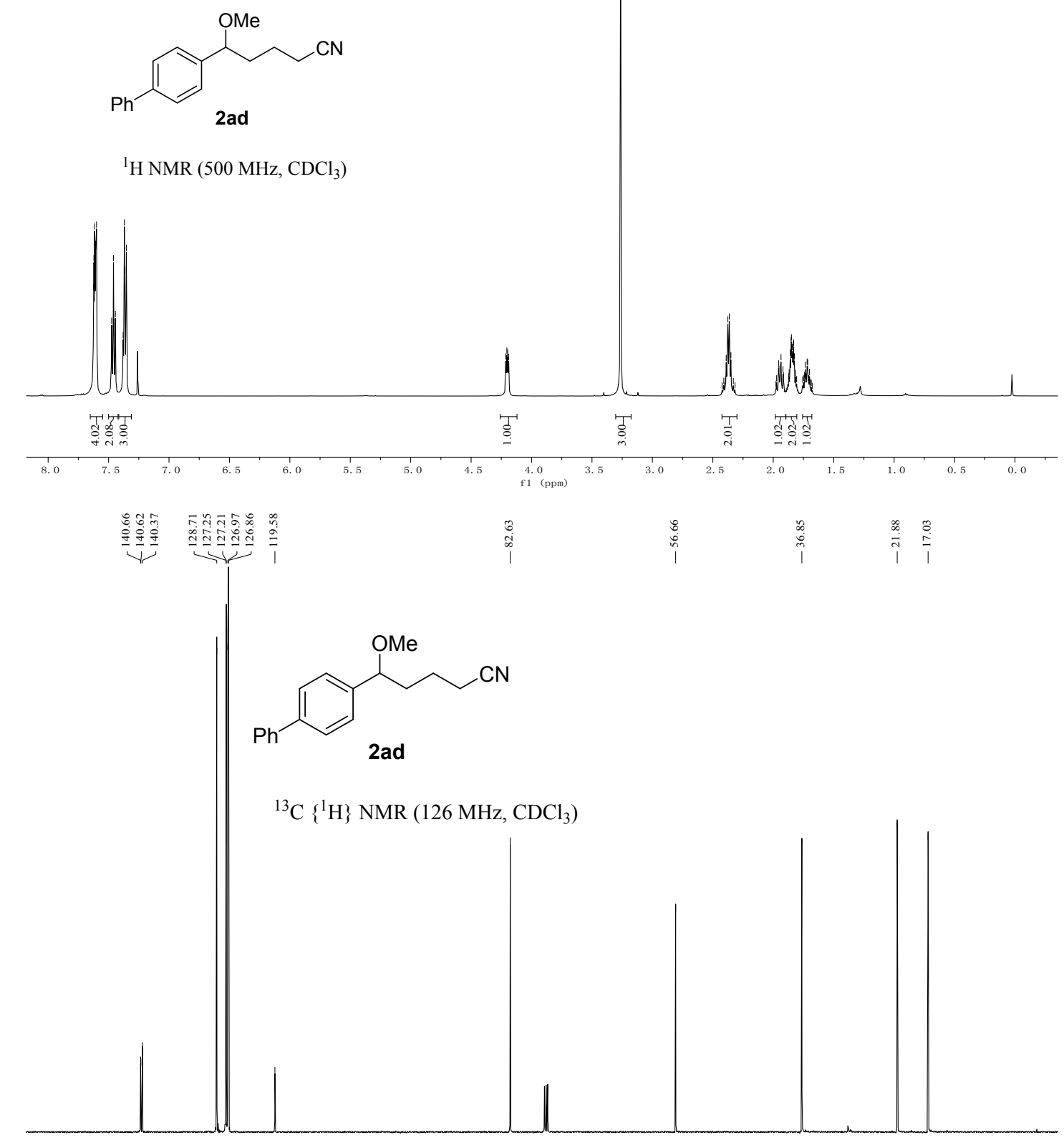

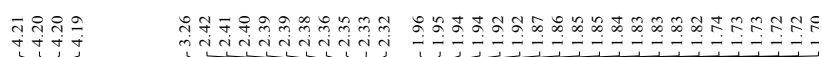

$\int 11$

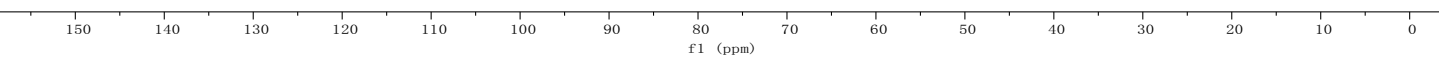




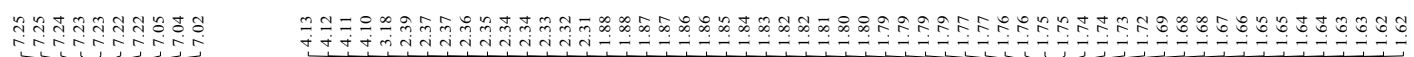<smiles>C1=CC=C1</smiles><smiles>COC(CCCC#N)c1ccc(F)cc1</smiles>

${ }^{1} \mathrm{H} \mathrm{NMR}\left(500 \mathrm{MHz}, \mathrm{CDCl}_{3}\right)$

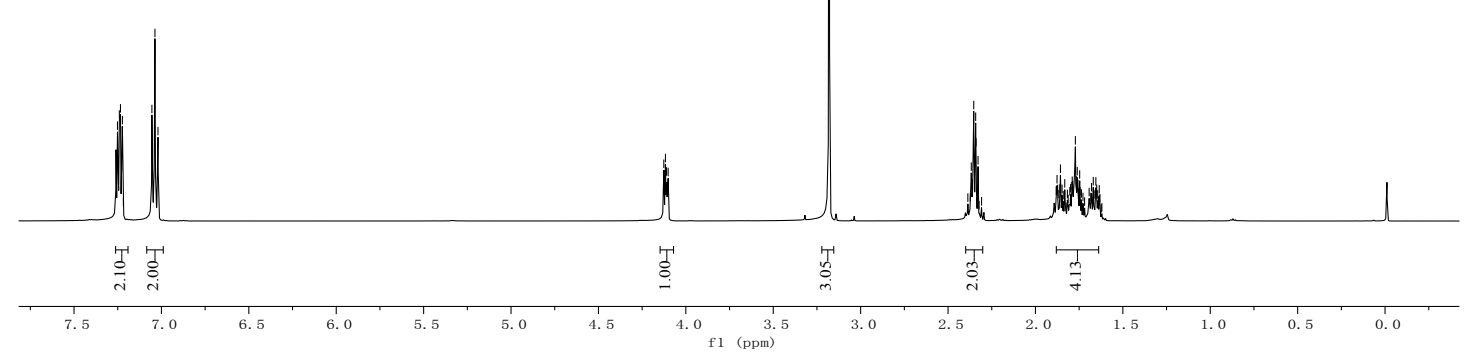

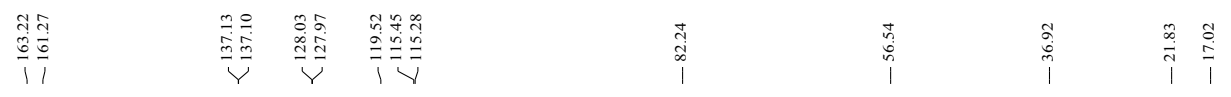<smiles>COC(CCCC#N)c1ccc(F)cc1</smiles>

${ }^{13} \mathrm{C}\left\{{ }^{1} \mathrm{H}\right\}$ NMR $\left(126 \mathrm{MHz}, \mathrm{CDCl}_{3}\right)$

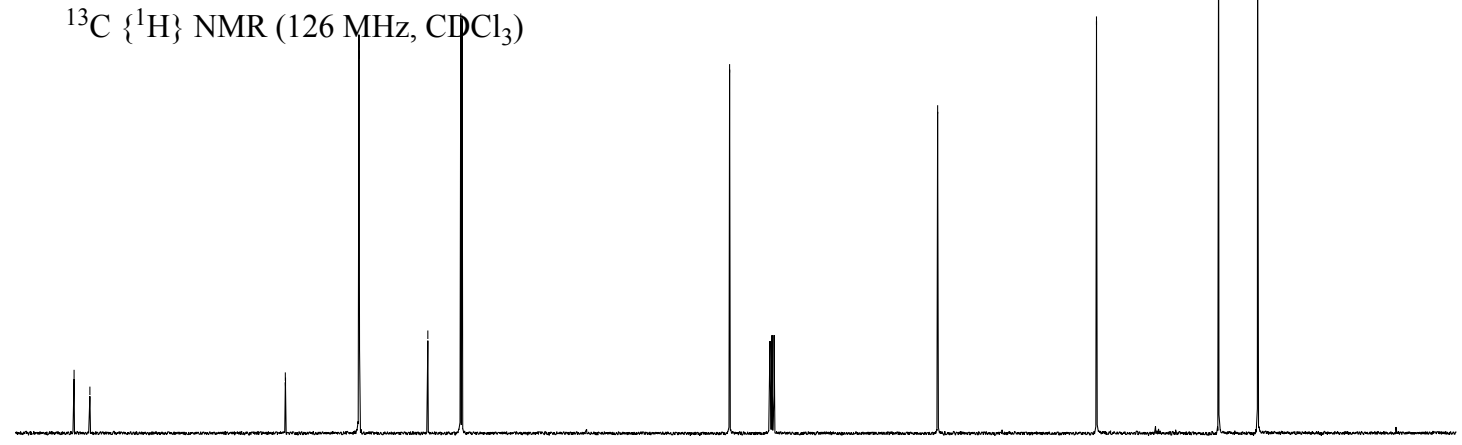

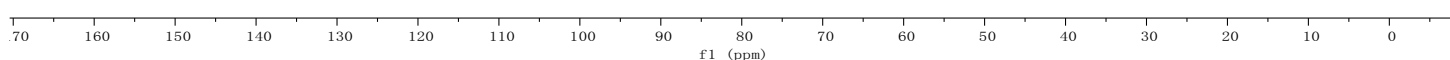


<smiles>COC(CCCC#N)c1ccc(F)cc1</smiles>

${ }^{19} \mathrm{~F}\left\{{ }^{1} \mathrm{H}\right\}$ NMR $\left(471 \mathrm{MHz}, \mathrm{CDCl}_{3}\right)$
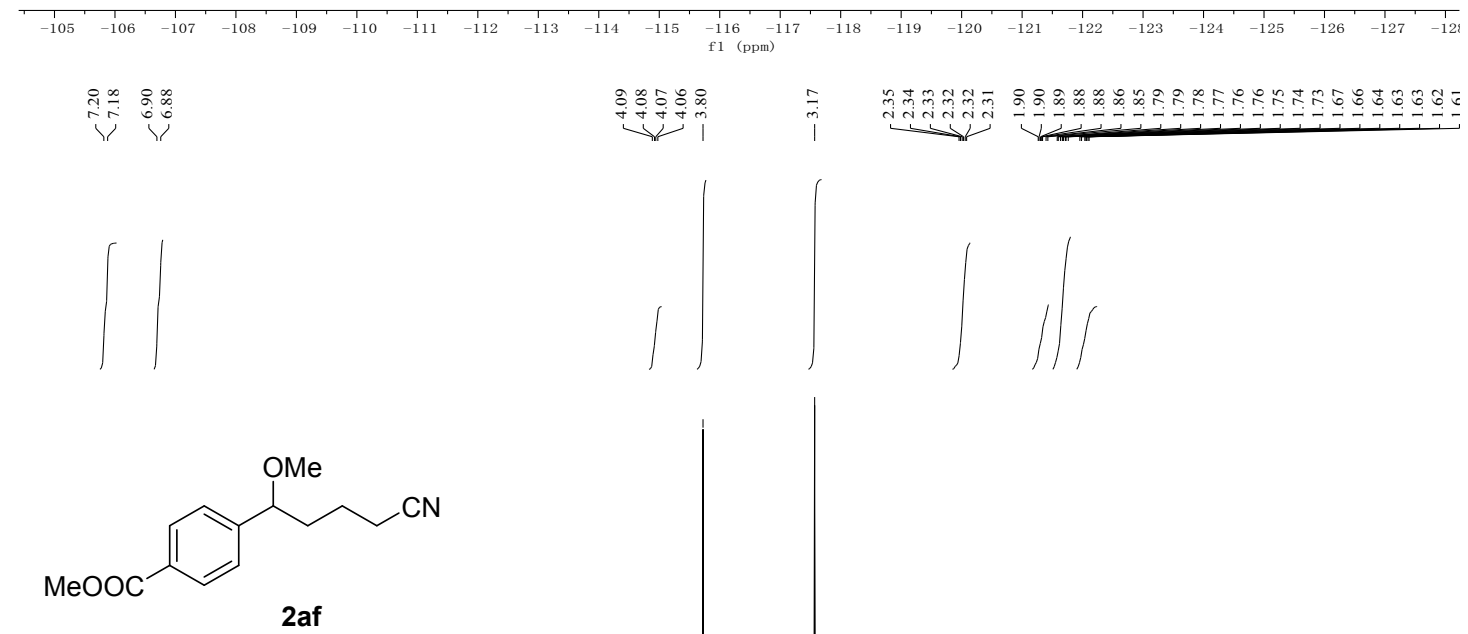

${ }^{1} \mathrm{H}$ NMR (400 MHz, $\mathrm{CDCl}_{3}$ )

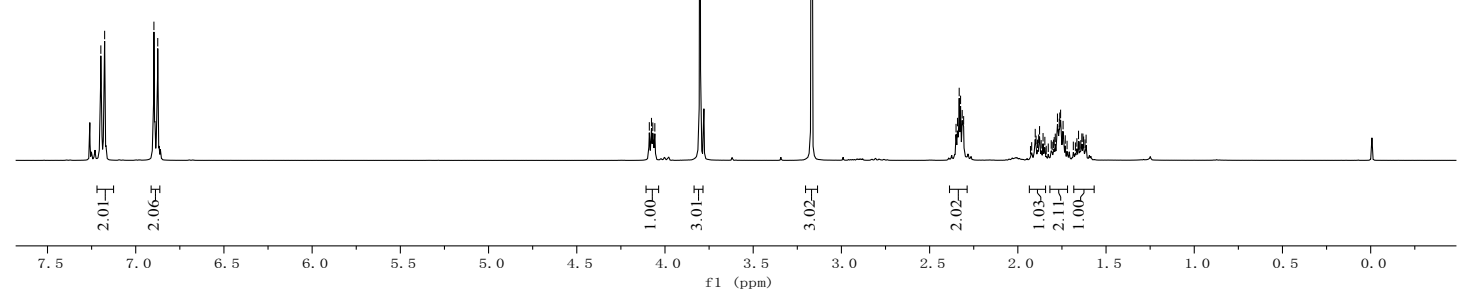




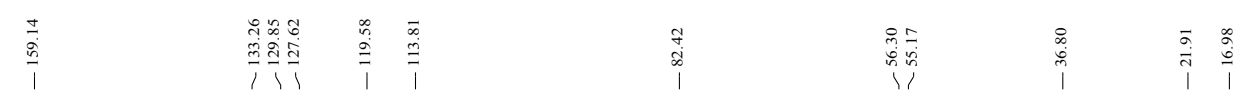<smiles>COC(CCCC#N)c1ccc(C(C)=O)cc1</smiles>

${ }^{13} \mathrm{C}\left\{{ }^{1} \mathrm{H}\right\}$ NMR $\left(100 \mathrm{MHz}, \mathrm{CDCl}_{3}\right)$
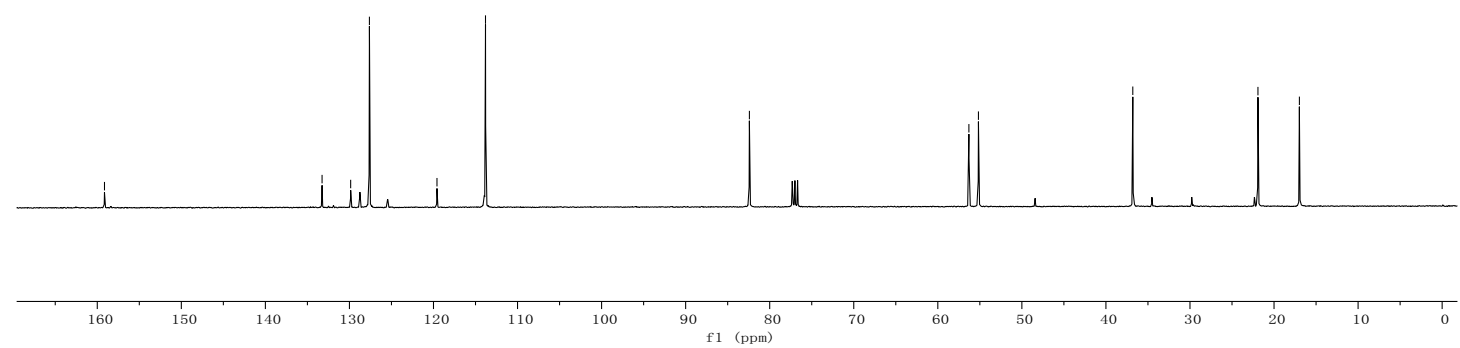

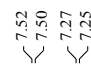

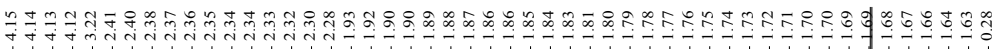
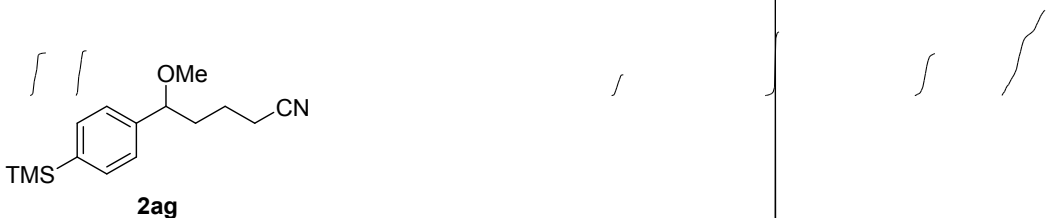

${ }^{1} \mathrm{H}$ NMR (400 MHz, $\left.\mathrm{CDCl}_{3}\right)$
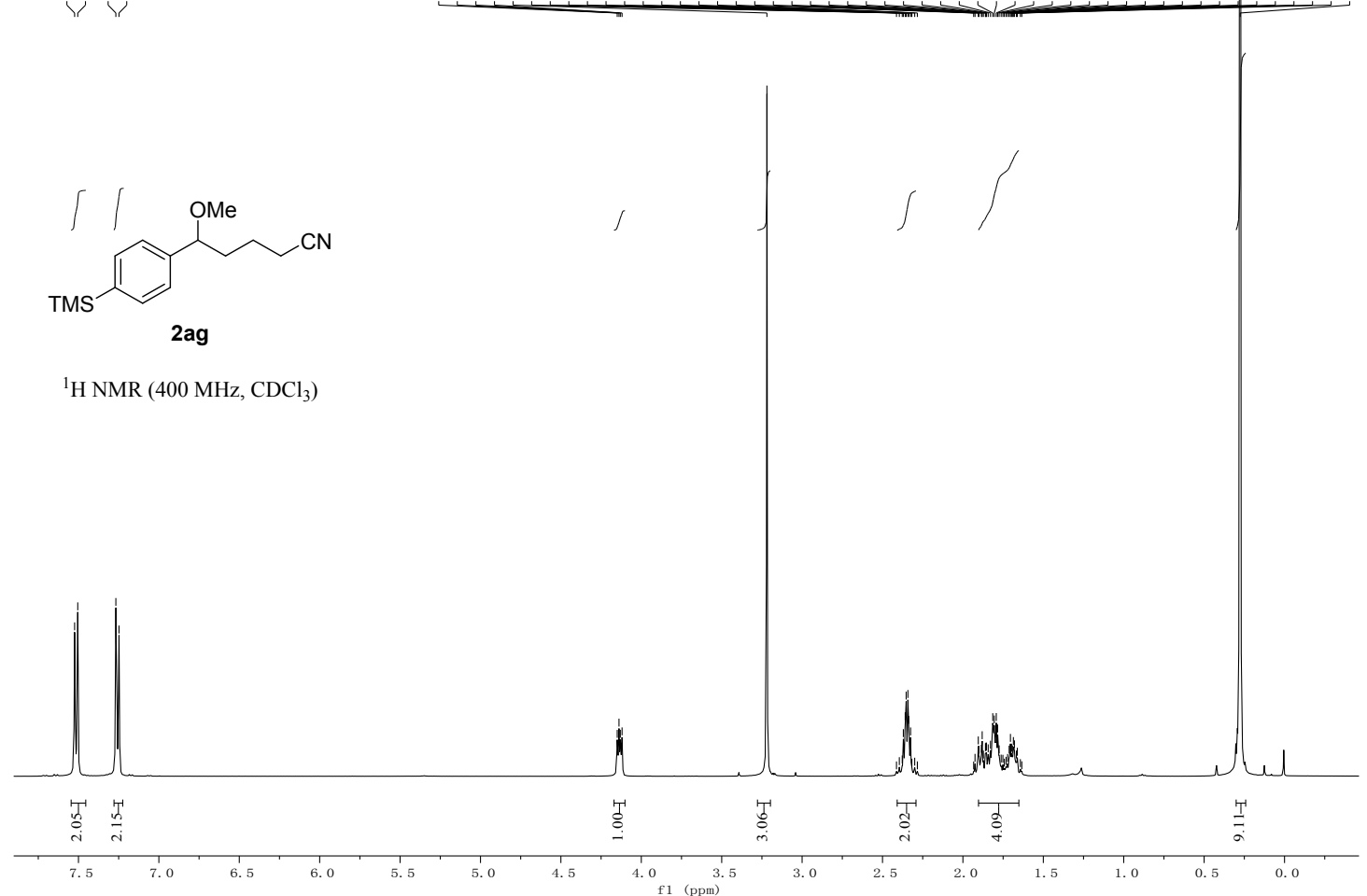


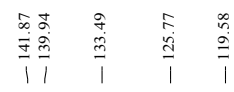
8
$\infty$
$\infty$

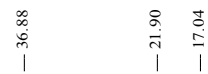
$\stackrel{0}{i}$<smiles>COC(CCCC#N)c1ccc([N+](=O)[O-])cc1</smiles>

${ }^{13} \mathrm{C}\left\{{ }^{1} \mathrm{H}\right\}$ NMR $\left(100 \mathrm{MHz}, \mathrm{CDCl}_{3}\right)$
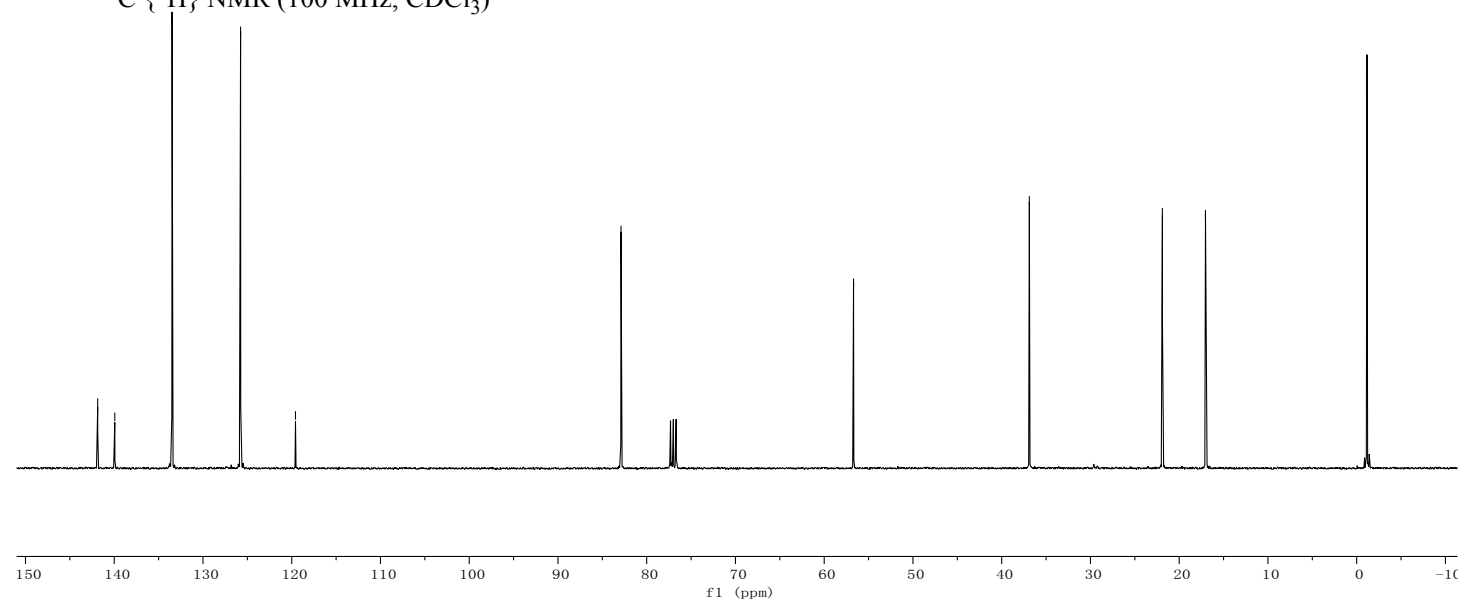

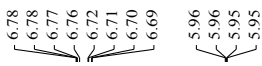

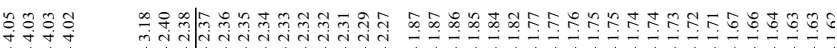

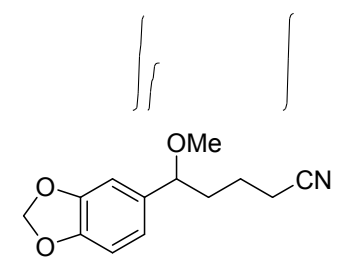

2ah

${ }^{1} \mathrm{H}$ NMR (400 MHz, $\mathrm{CDCl}_{3}$ )

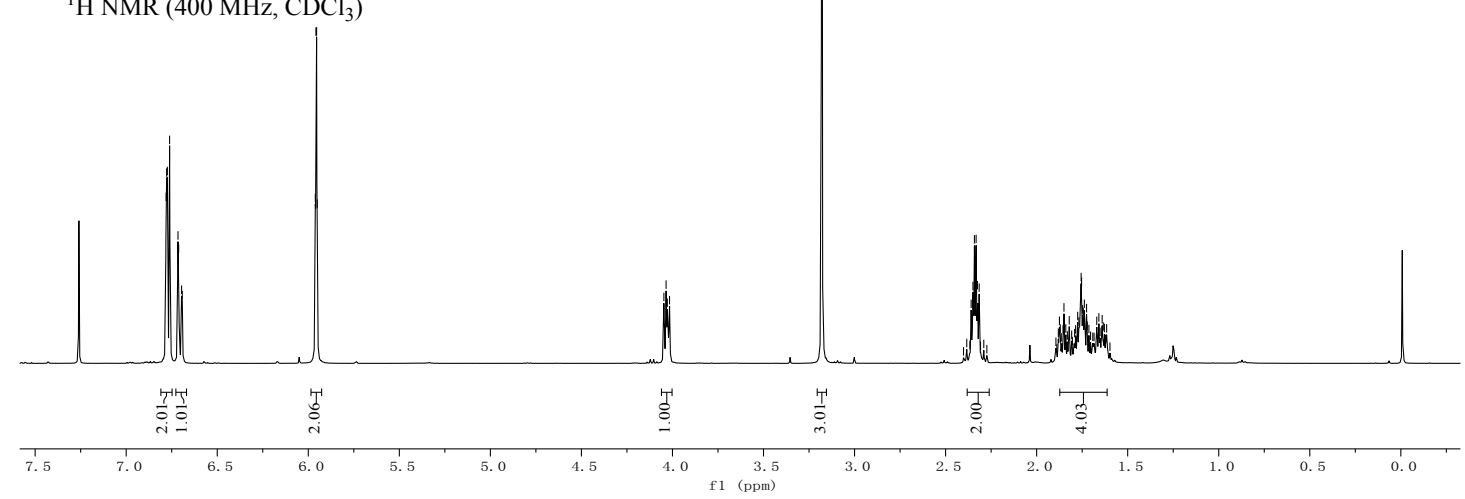




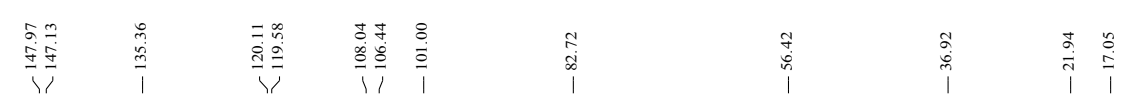<smiles>COC(CCCC#N)c1ccc2c(c1)OCO2</smiles>

2ah
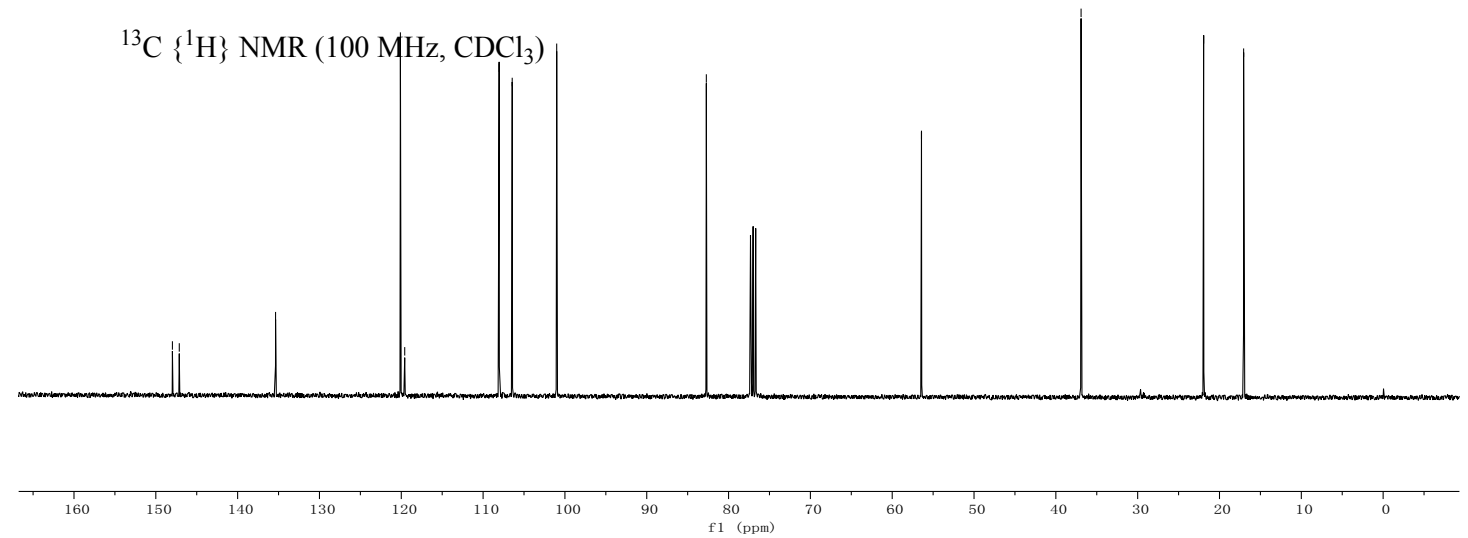

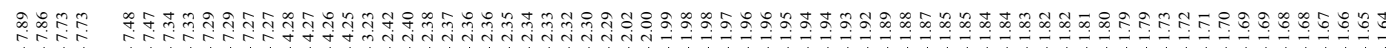
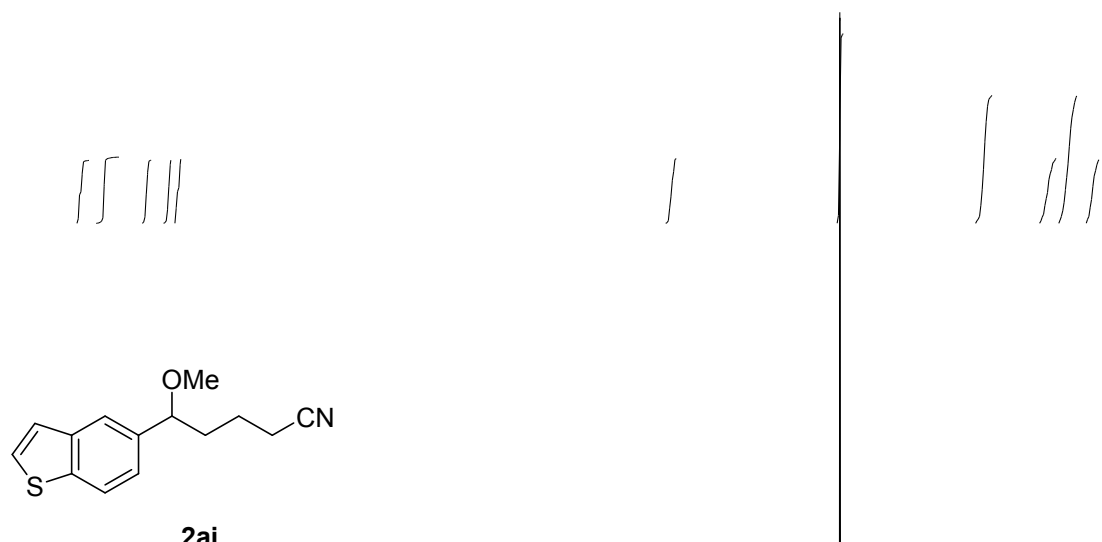

2ai

${ }^{1} \mathrm{H}$ NMR (400 MHz, $\mathrm{CDCl}_{3}$ )

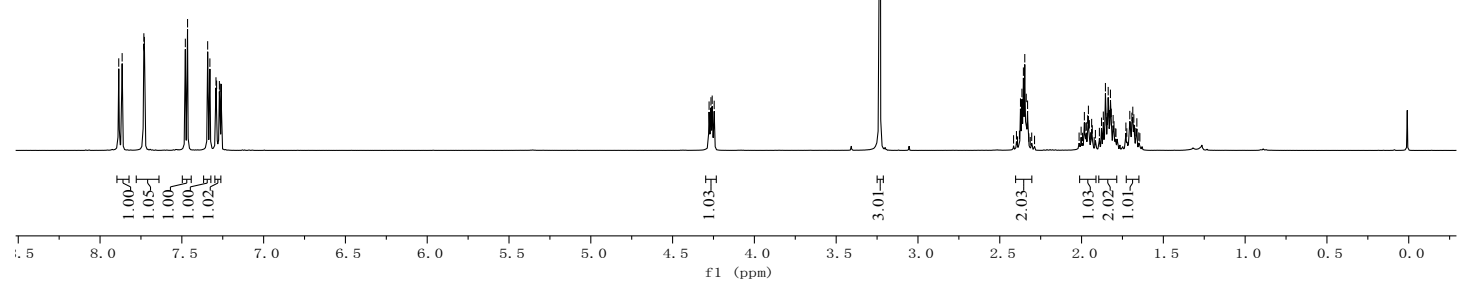




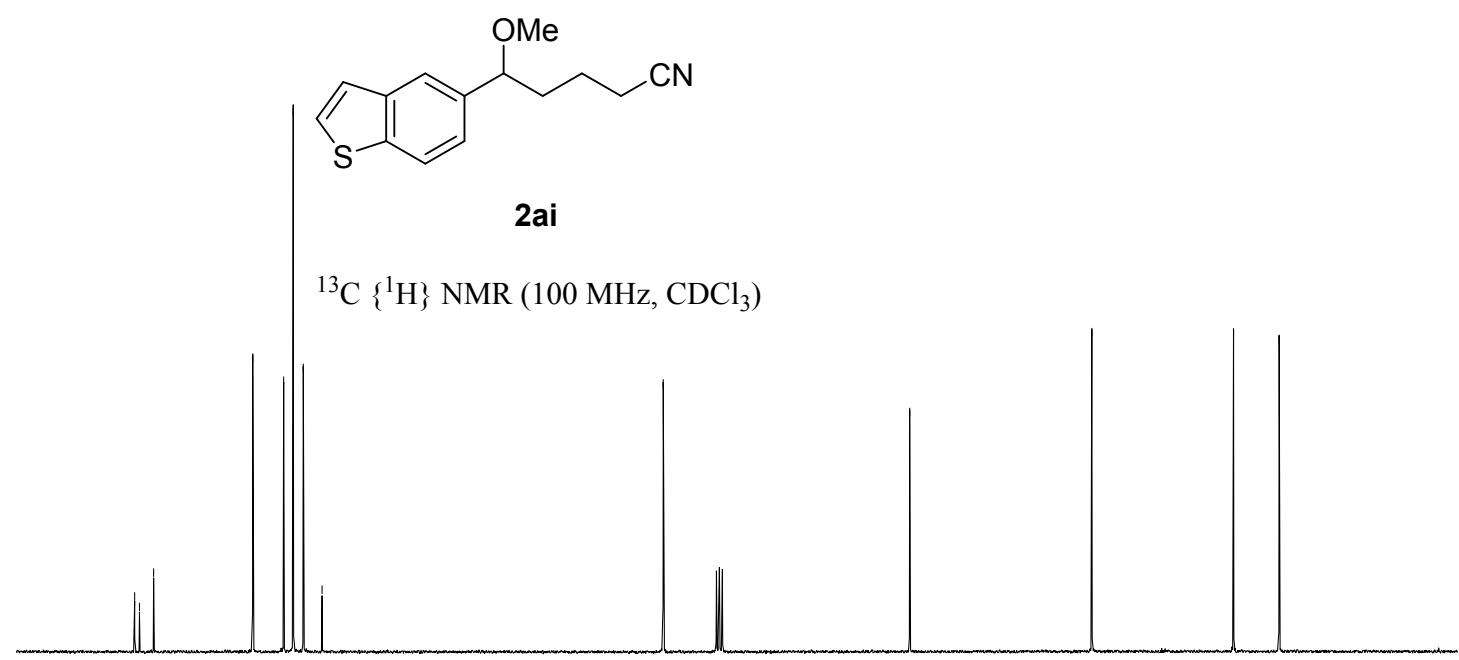

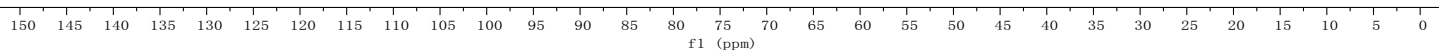

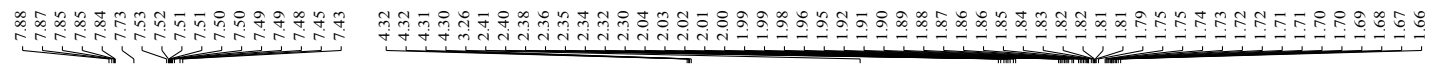
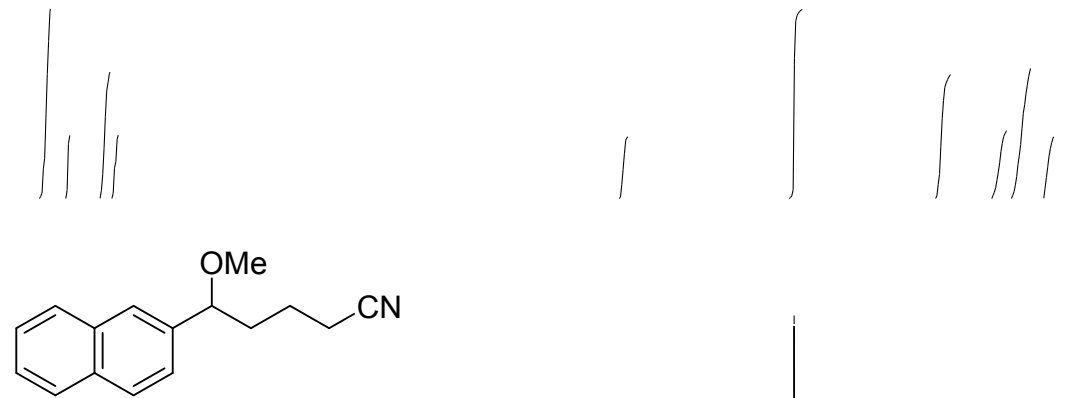

2aj

${ }^{1} \mathrm{H}$ NMR $\left(600 \mathrm{MHz}, \mathrm{CDCl}_{3}\right)$

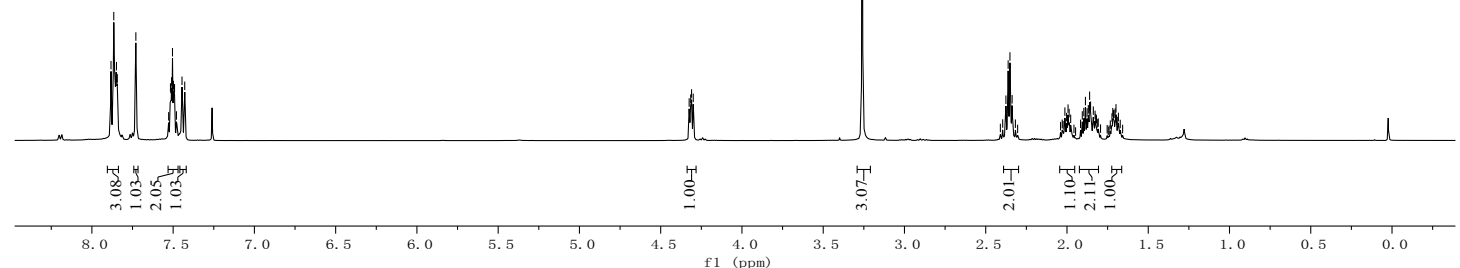


<smiles>COC(CCCC#N)c1ccc2ccccc2c1</smiles>

2aj

${ }^{13} \mathrm{C}\left\{{ }^{1} \mathrm{H}\right\}$ NMR $\left(151 \mathrm{MHz}, \mathrm{CDCl}_{3}\right)$
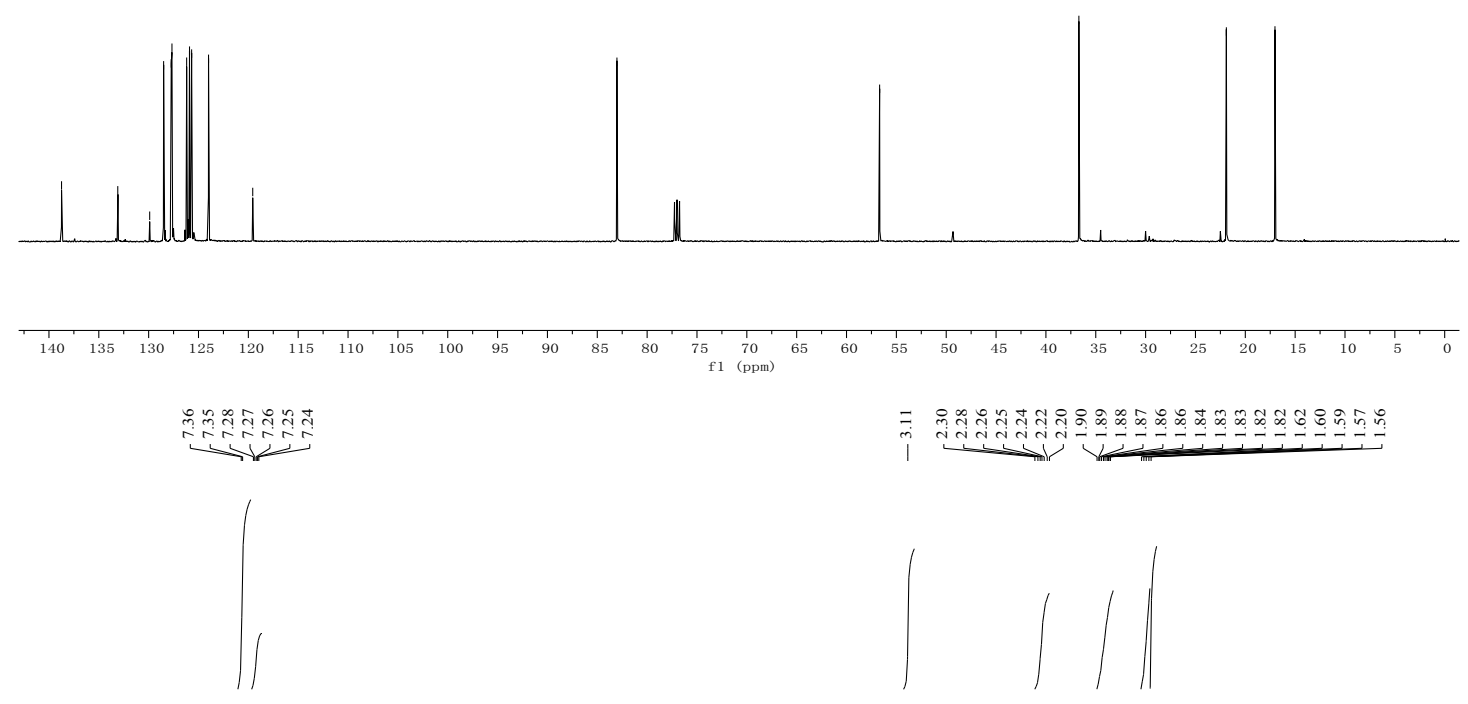<smiles>COC(C)(CCCC#N)c1ccccc1</smiles>

2ak

${ }^{1} \mathrm{H} \mathrm{NMR}\left(500 \mathrm{MHz}, \mathrm{CDCl}_{3}\right)$

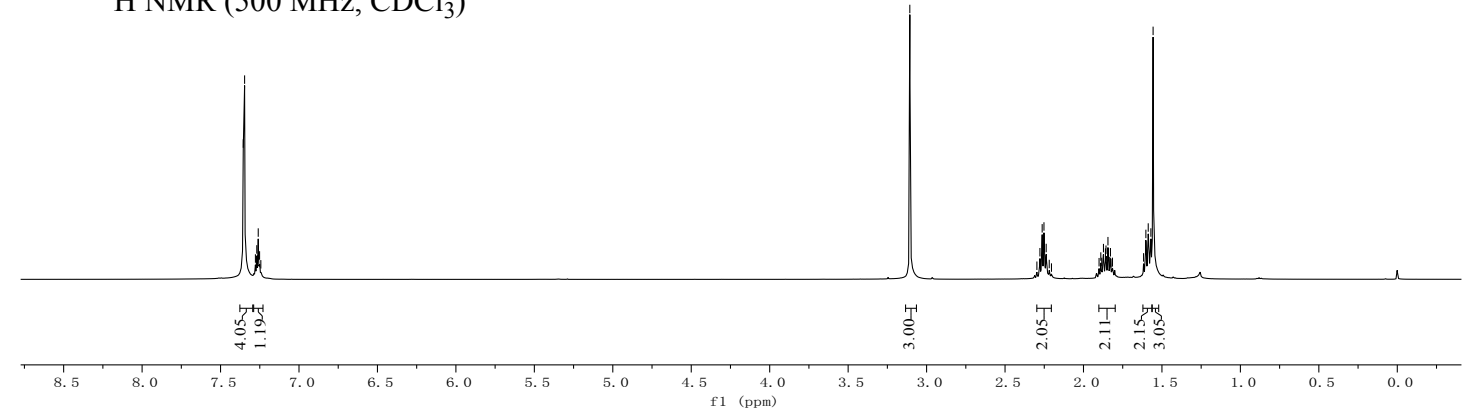




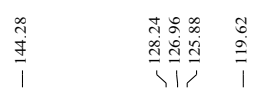

$\underset{\substack{0 \\ \infty}}{\substack{\infty \\ i}}$

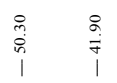

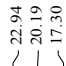<smiles>COC(C)(CCCC#N)c1ccccc1</smiles>

\section{2ak}

${ }^{13} \mathrm{C}\left\{{ }^{1} \mathrm{H}\right\}$ NMR $\left(126 \mathrm{MHz}, \mathrm{CDCl}_{3}\right)$
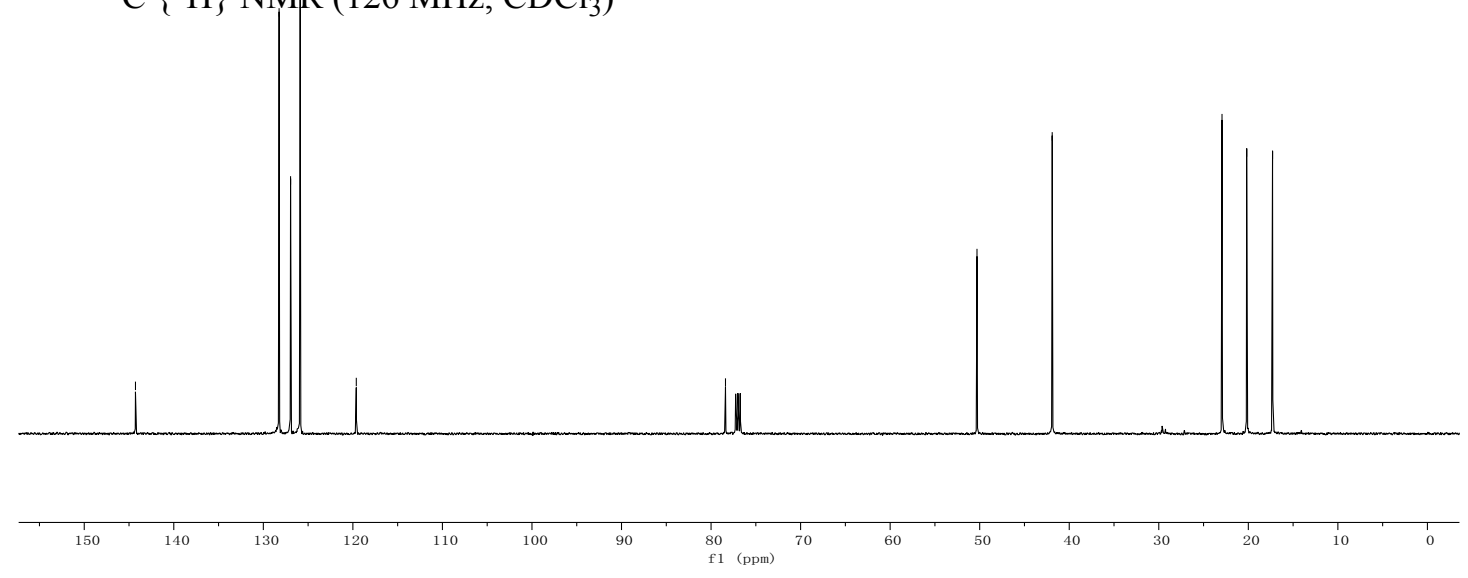

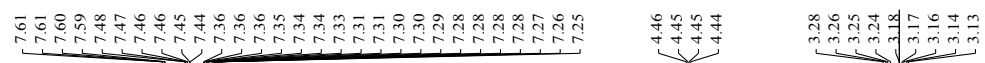

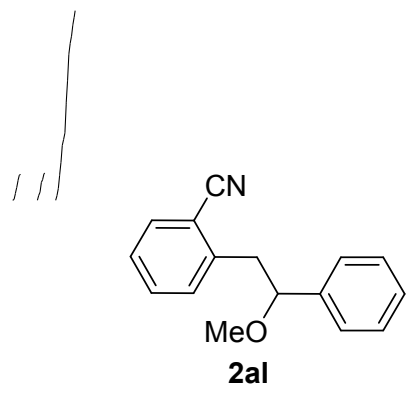

${ }^{1} \mathrm{H} \mathrm{NMR}\left(500 \mathrm{MHz}, \mathrm{CDCl}_{3}\right)$

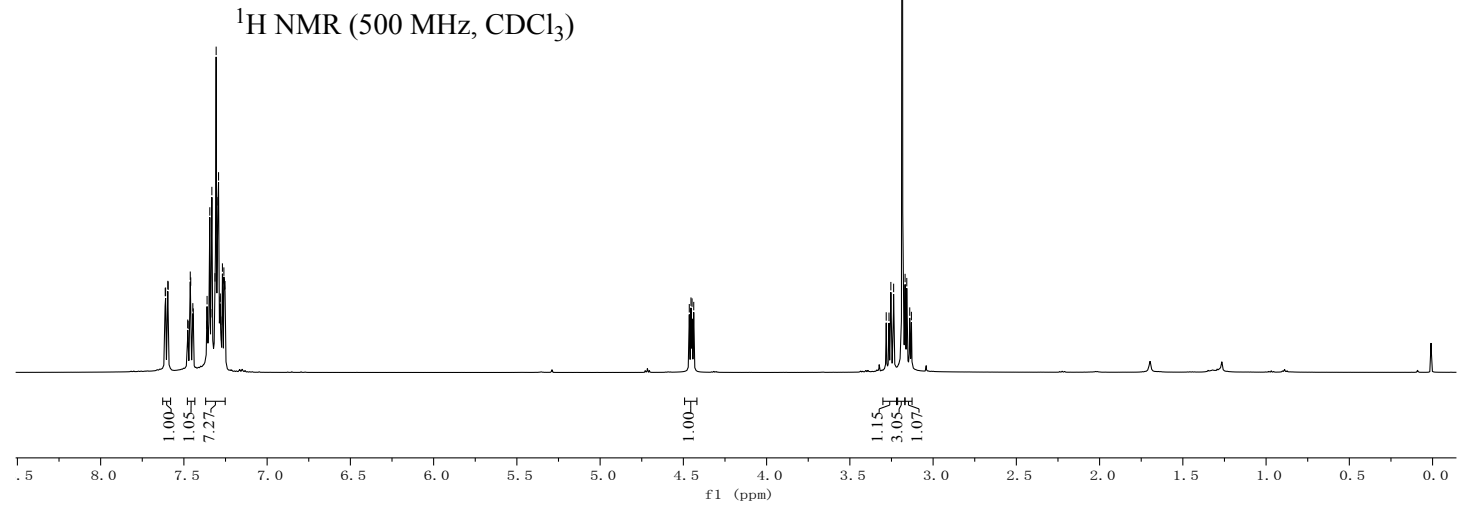



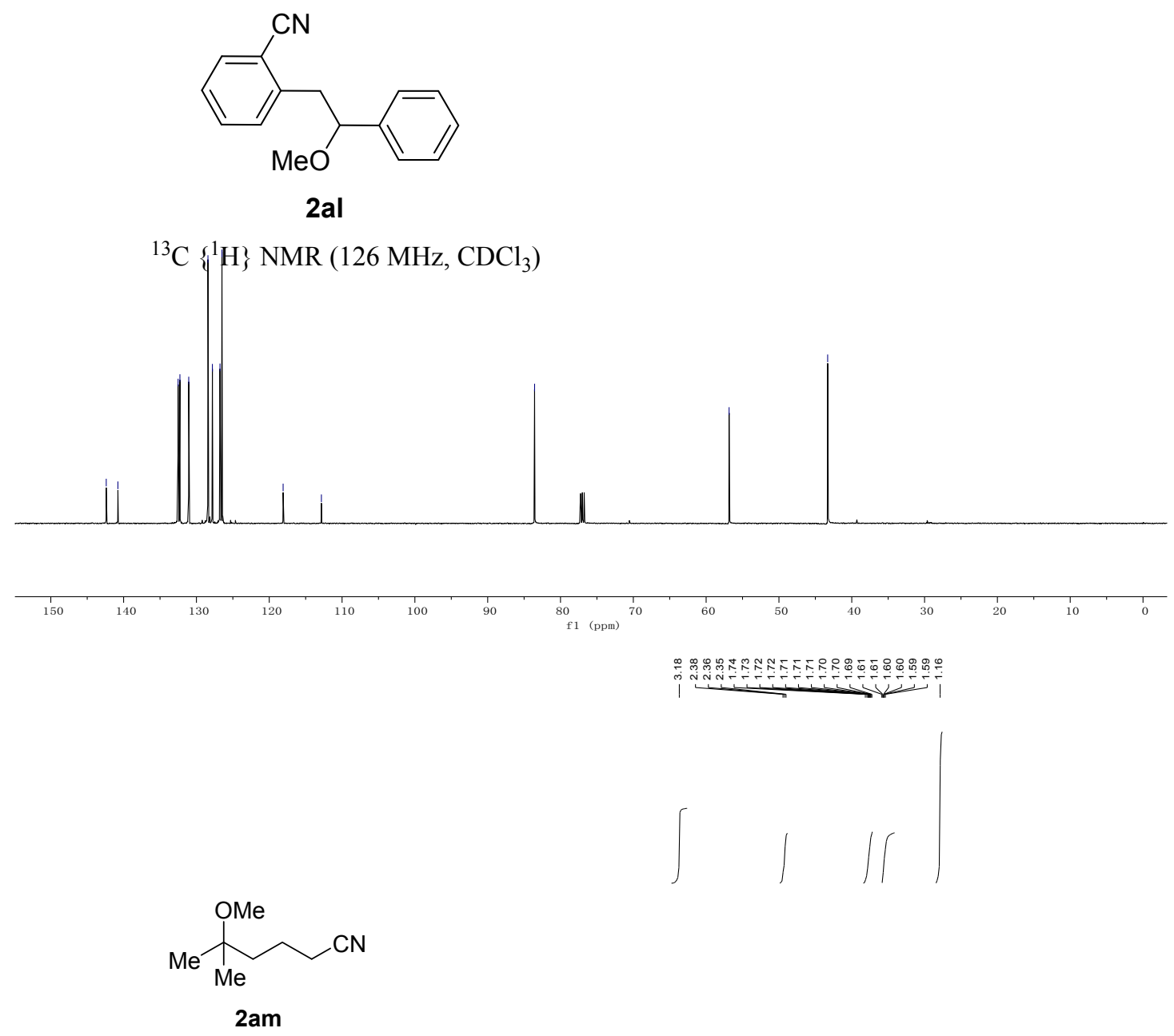

${ }^{1} \mathrm{H}$ NMR (600 MHz, $\mathrm{CDCl}_{3}$ )

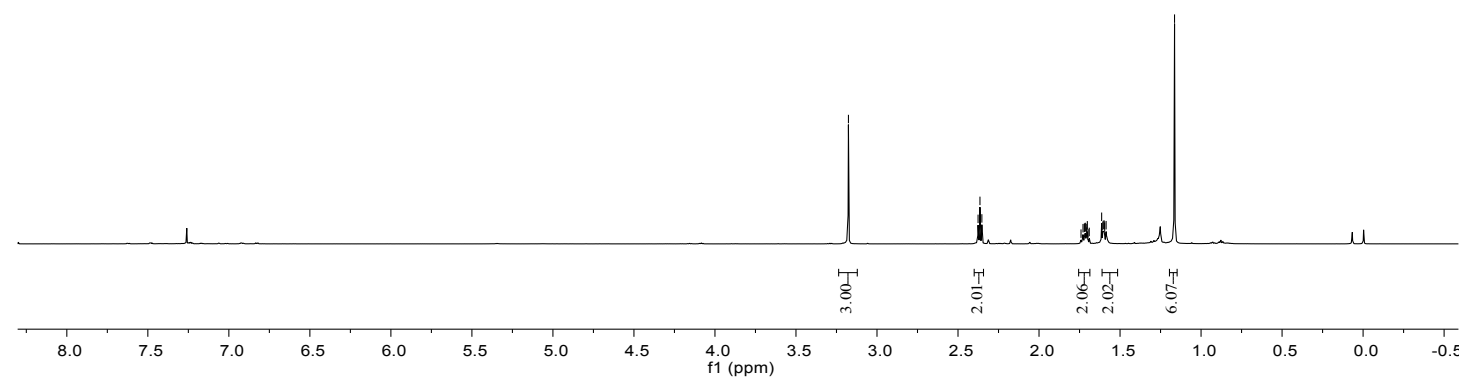


\begin{tabular}{l}
$\hat{k}$ \\
$\stackrel{0}{+}$ \\
\hline
\end{tabular}<smiles>COC(C)(C)CCCC#N</smiles>

${ }^{13} \mathrm{C}\left\{{ }^{1} \mathrm{H}\right\} \mathrm{NMR}(151 \mathrm{MHz}, \mathrm{CDCCl})$

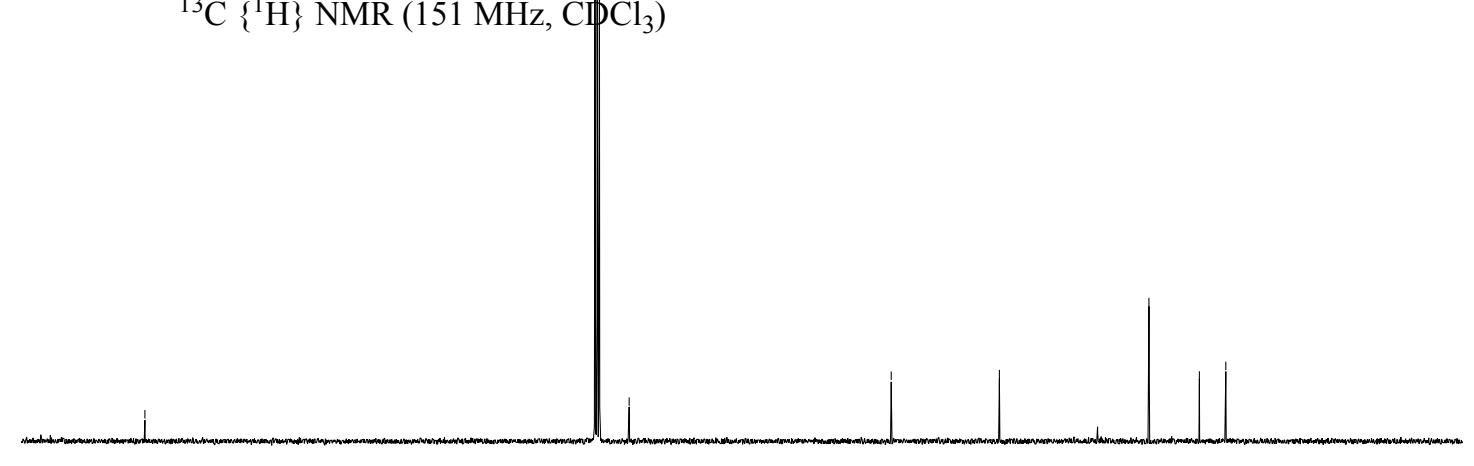

$\begin{array}{llllllllllllllllllllllllllllllllllllllll}130 & 125 & 120 & 115 & 110 & 105 & 100 & 95 & 90 & 85 & 80 & 75 & 70 & 65 & 60 & 55 & 50 & 45 & 40 & 35 & 30 & 25 & 20 & 15 & 10 & 5 & 0\end{array}$

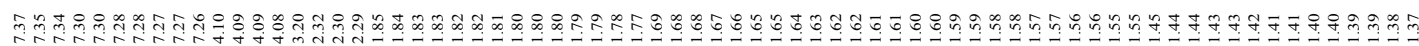
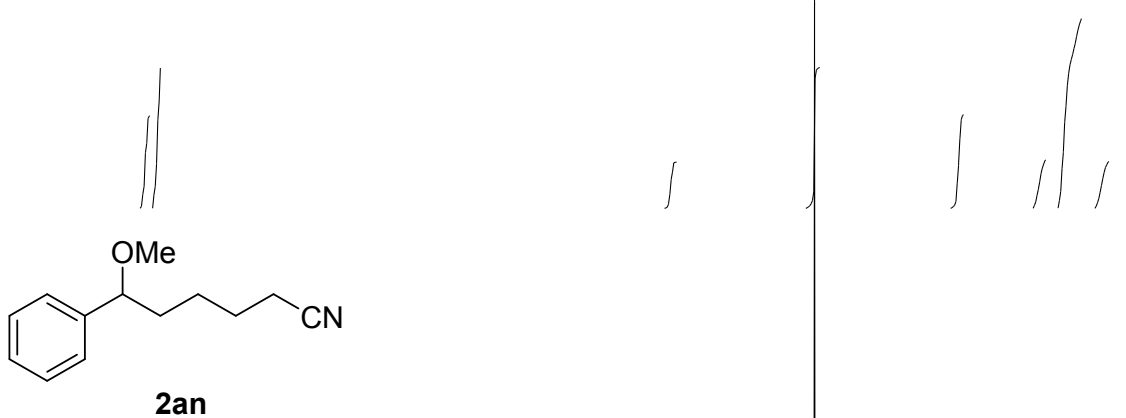

${ }^{1} \mathrm{H} \mathrm{NMR}\left(500 \mathrm{MHz}, \mathrm{CDCl}_{3}\right)$

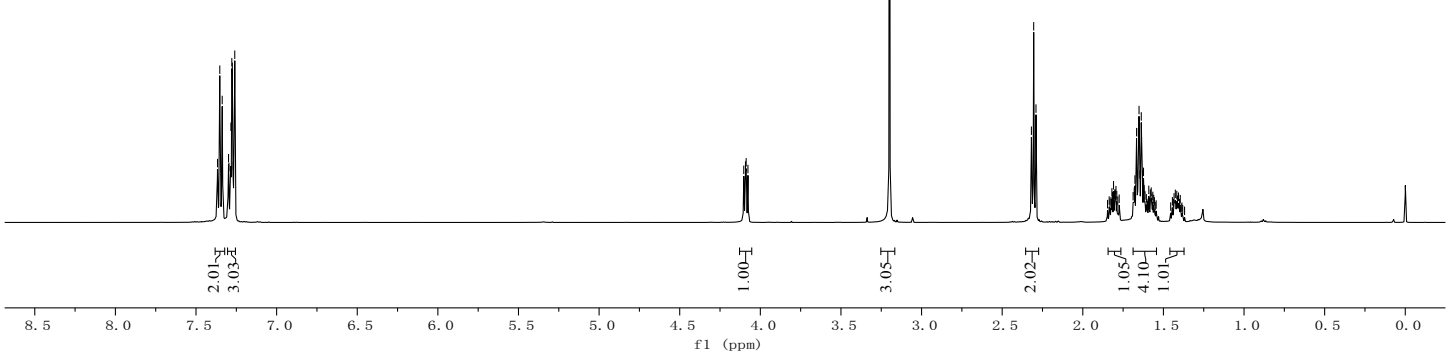



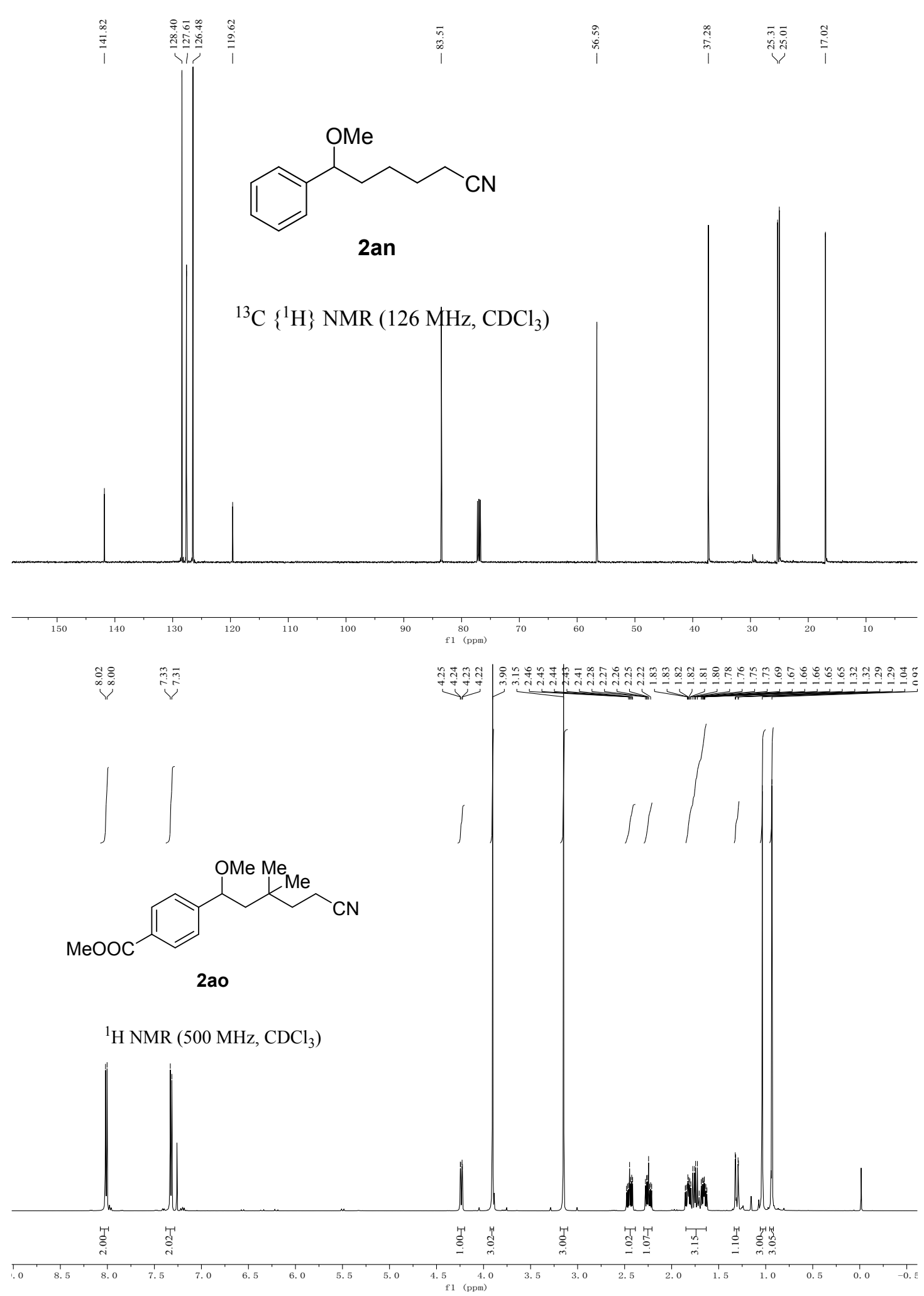

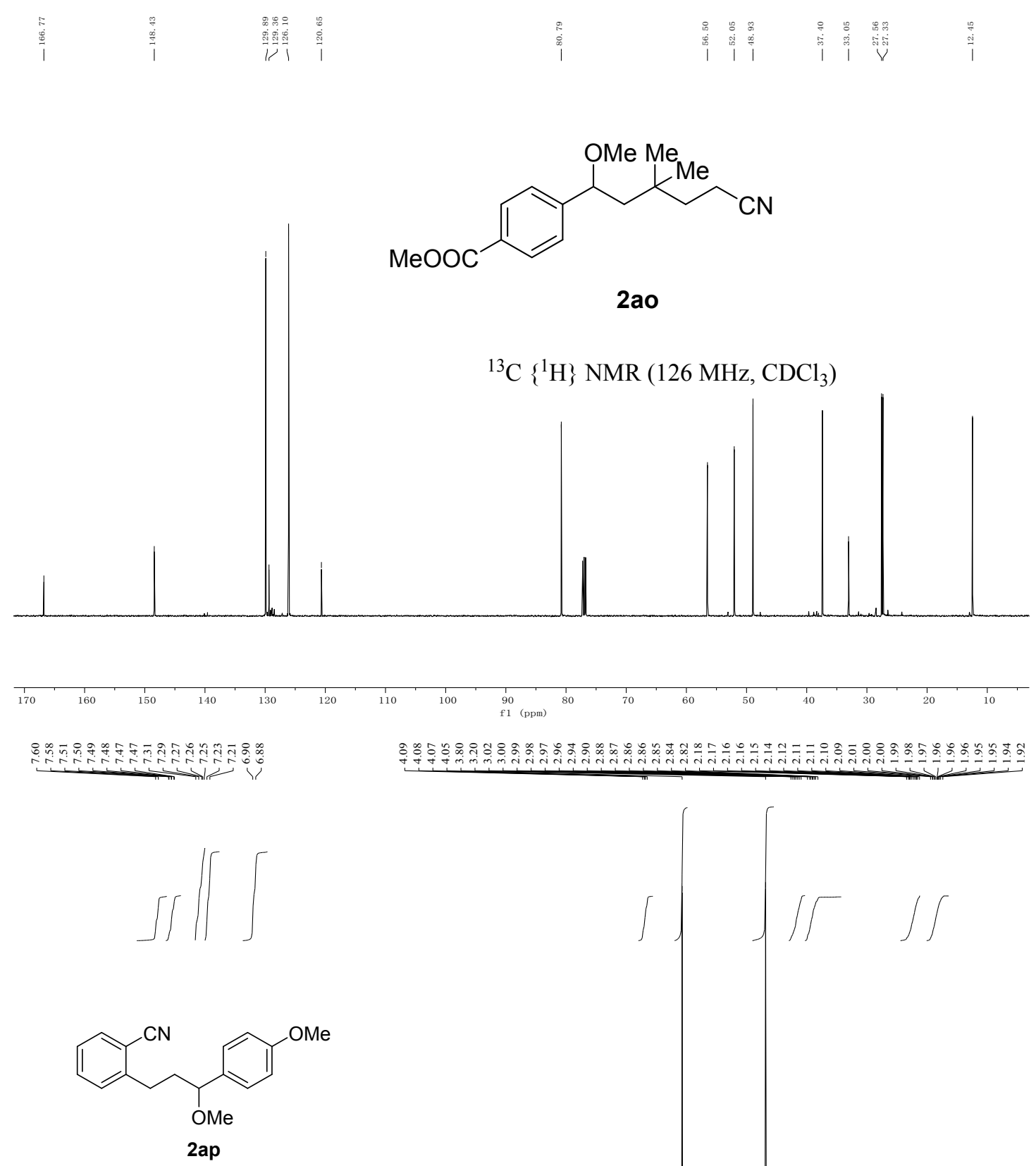

${ }^{1} \mathrm{H}$ NMR (400 MHz, $\mathrm{CDCl}_{3}$ )

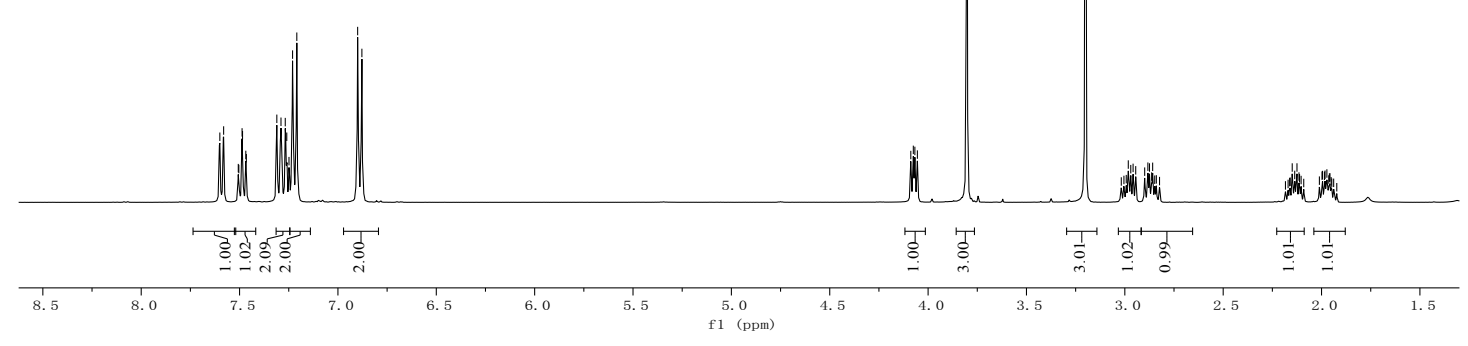




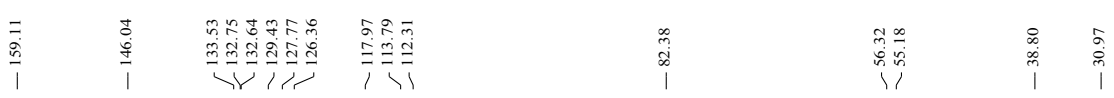
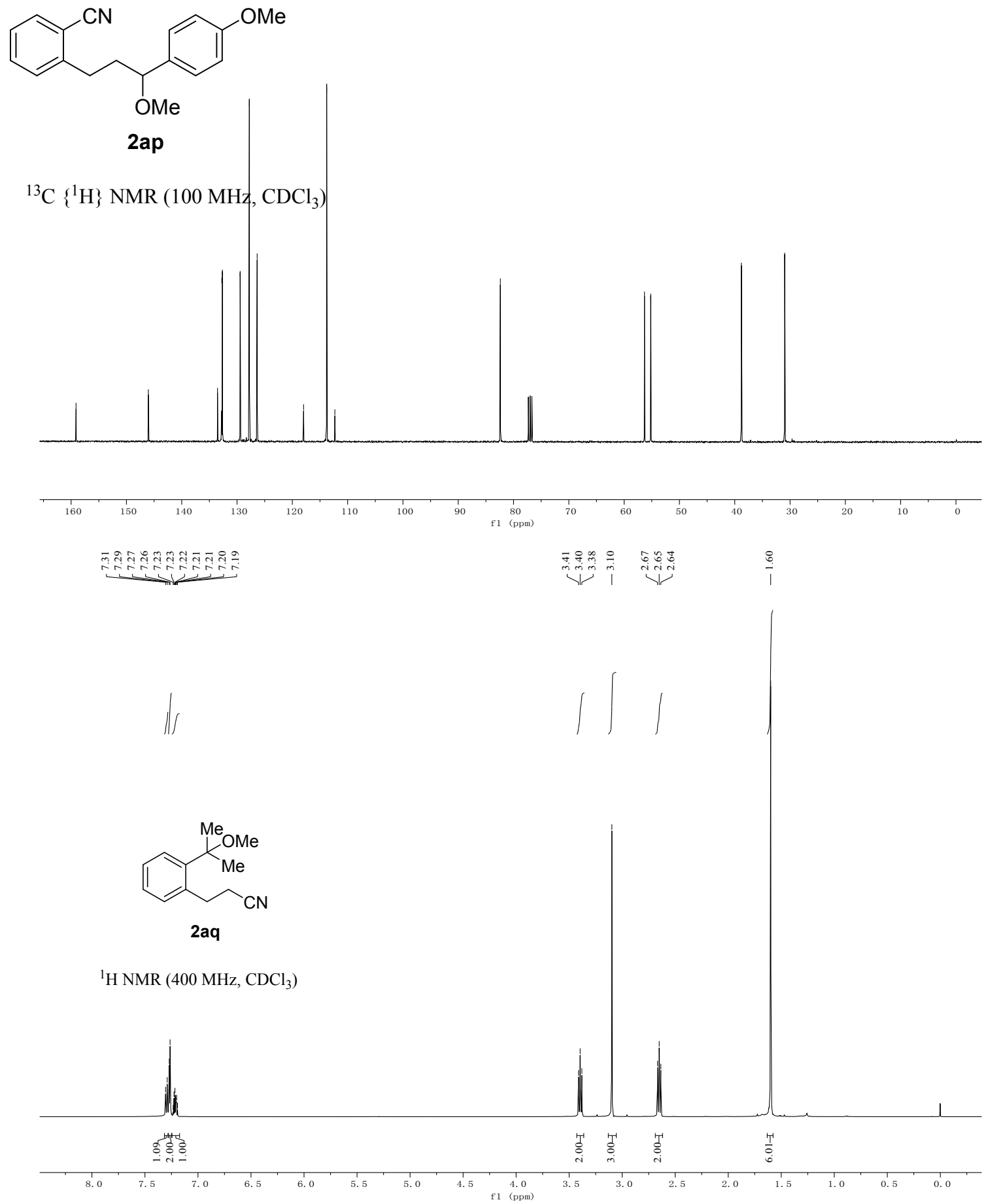


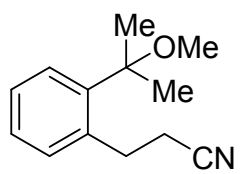

2aq

${ }^{13} \mathrm{C}\left\{{ }^{1} \mathrm{H}\right\}$ NMR $\left(100 \mathrm{MHz}, \mathrm{CDCl}_{3}\right)$
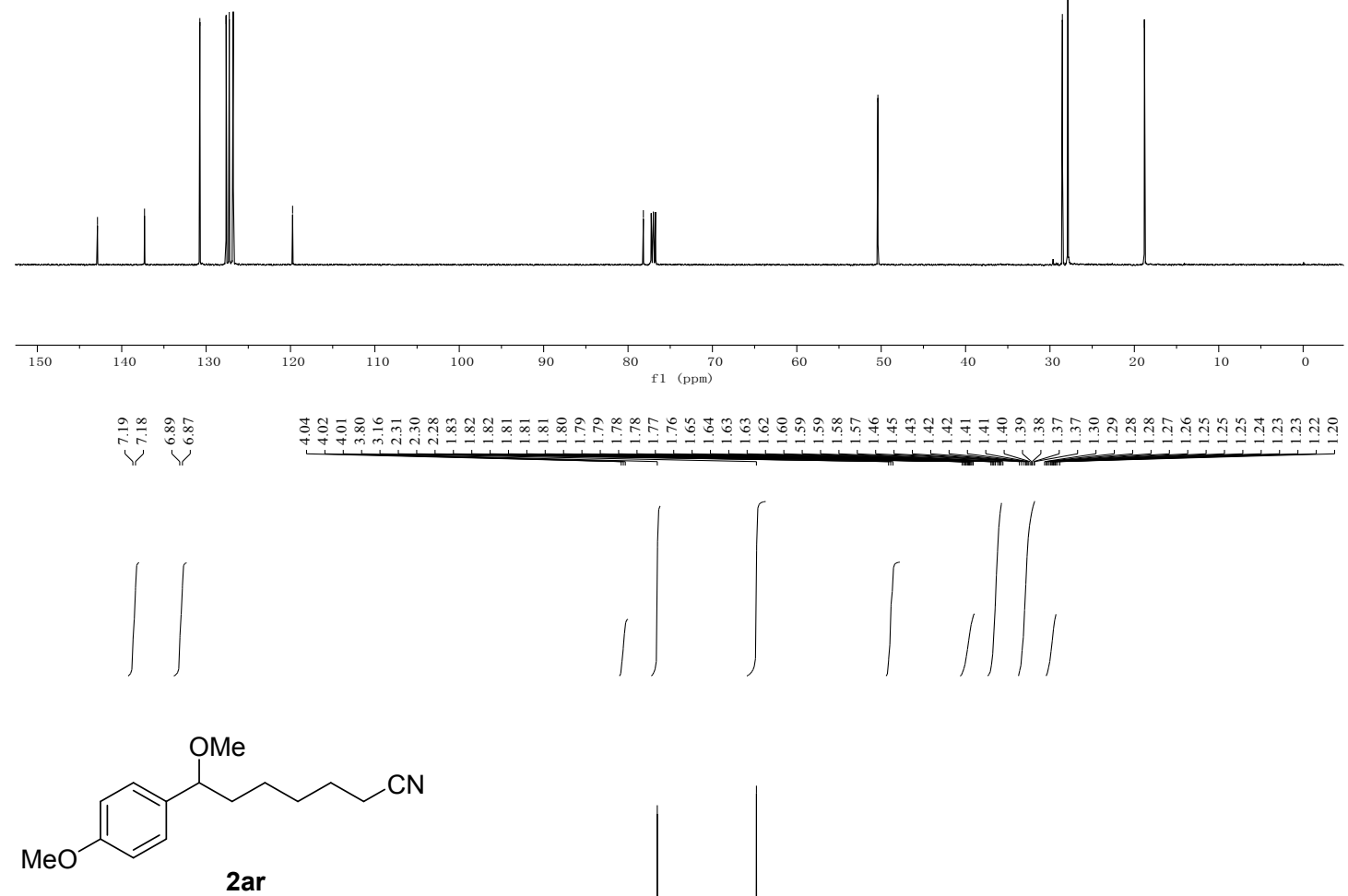

${ }^{1} \mathrm{H}$ NMR $\left(500 \mathrm{MHz}, \mathrm{CDCl}_{3}\right)$

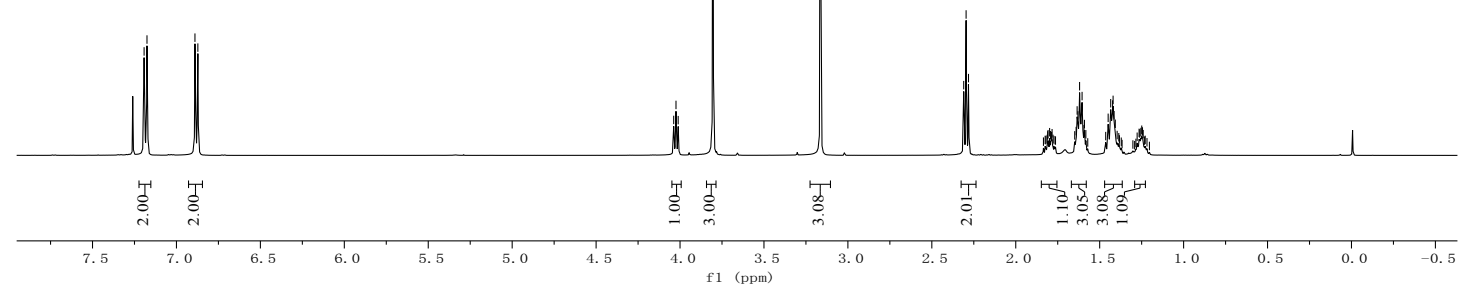



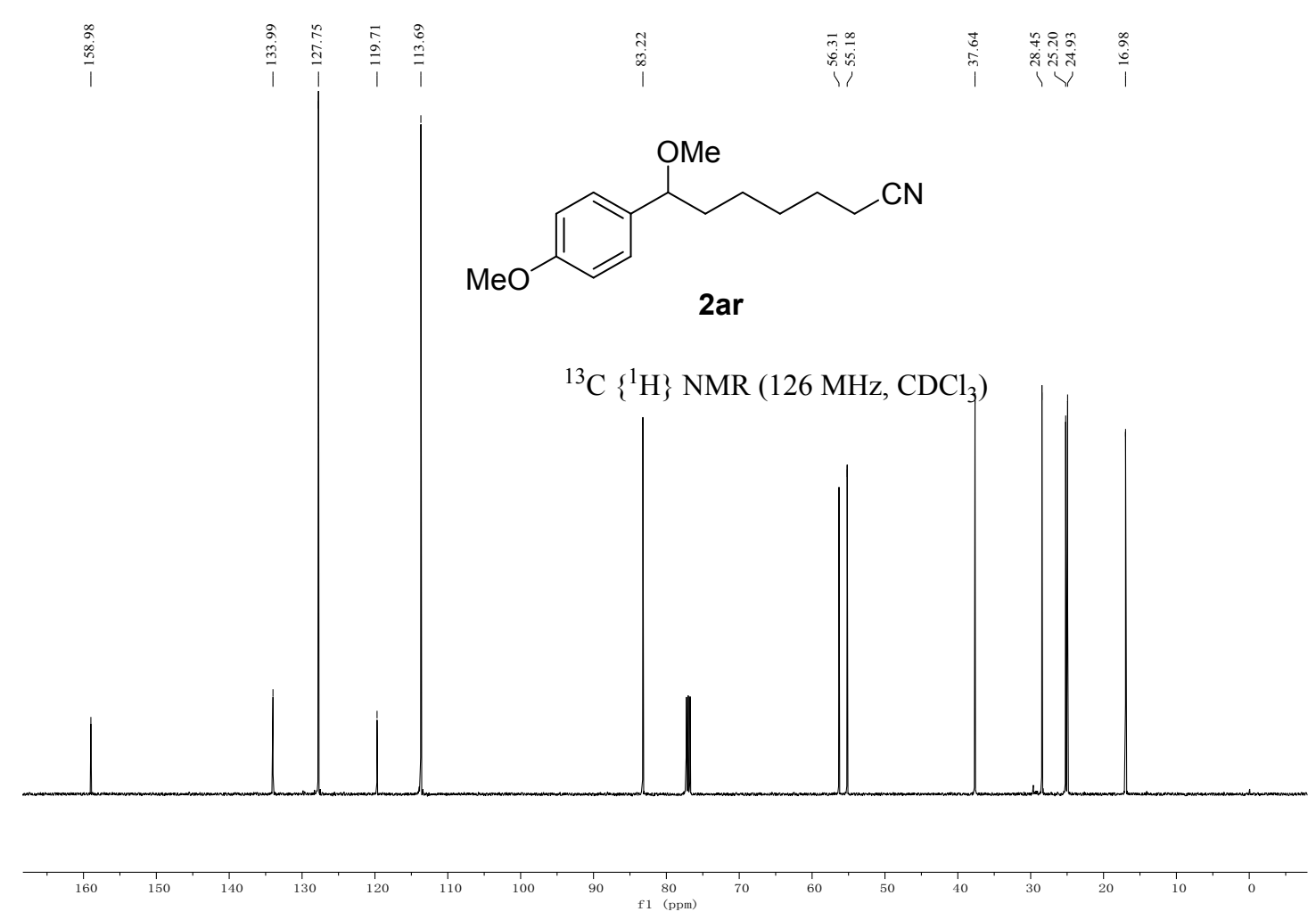

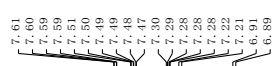
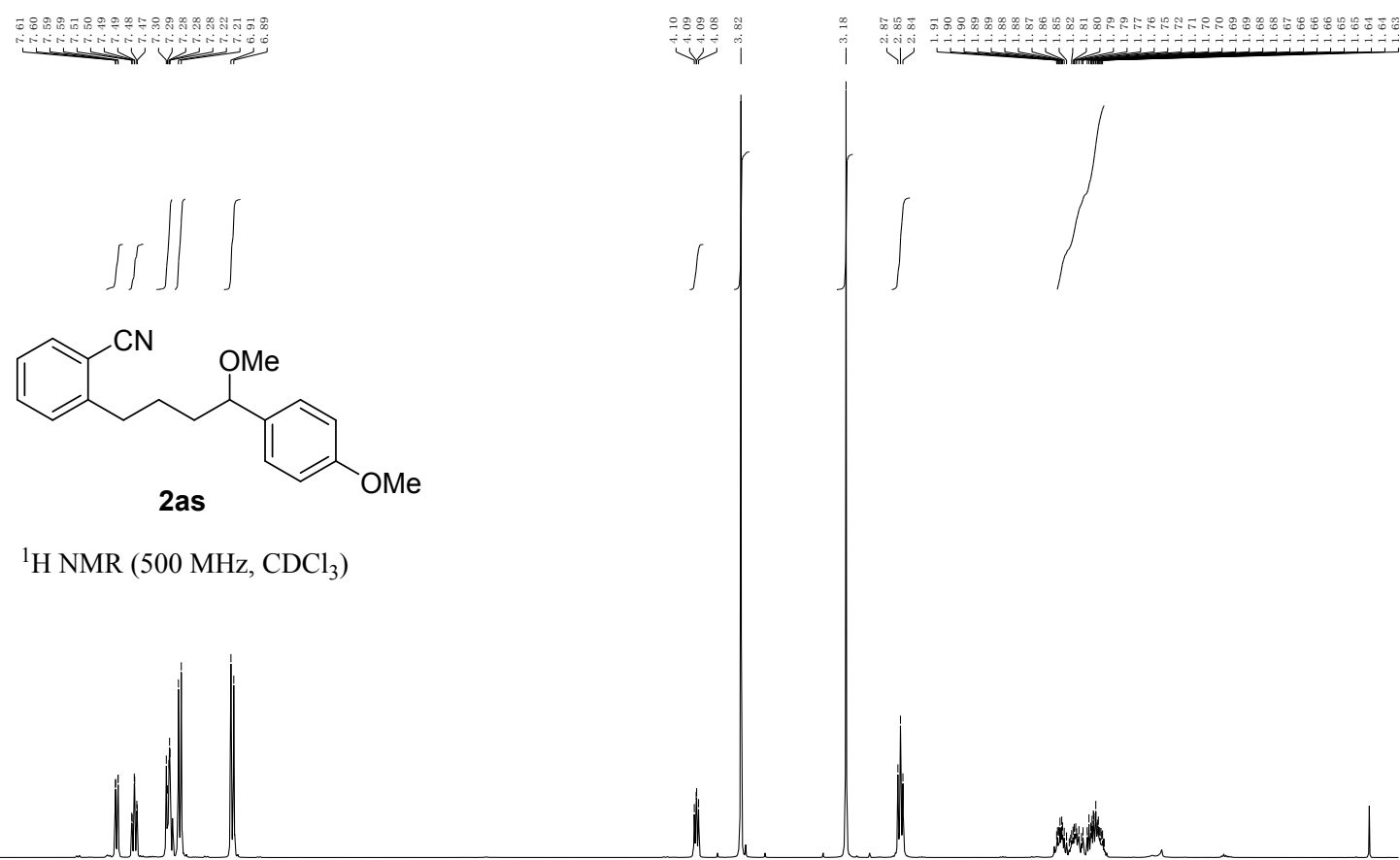

${ }^{1} \mathrm{H}$ NMR (500 MHz, $\mathrm{CDCl}_{3}$ )

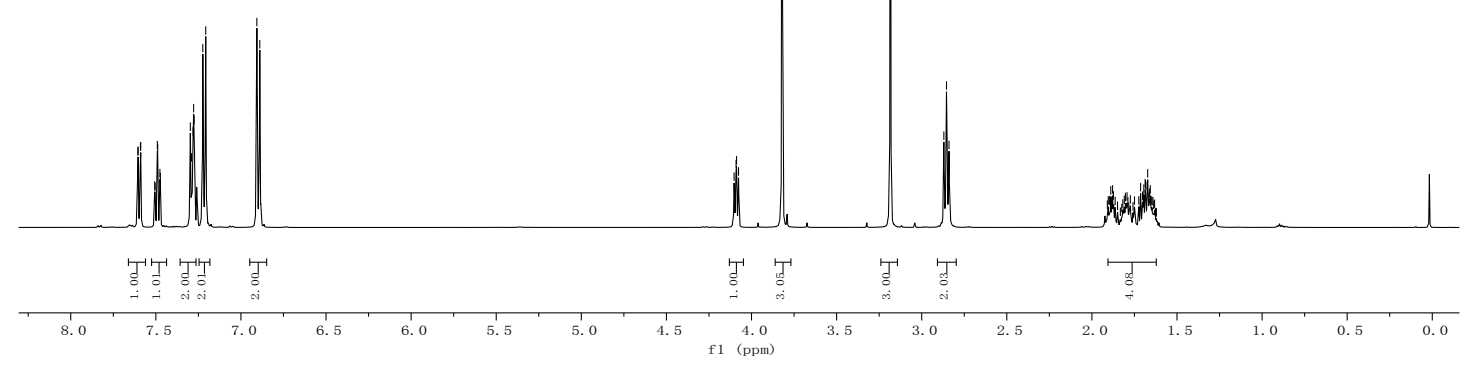



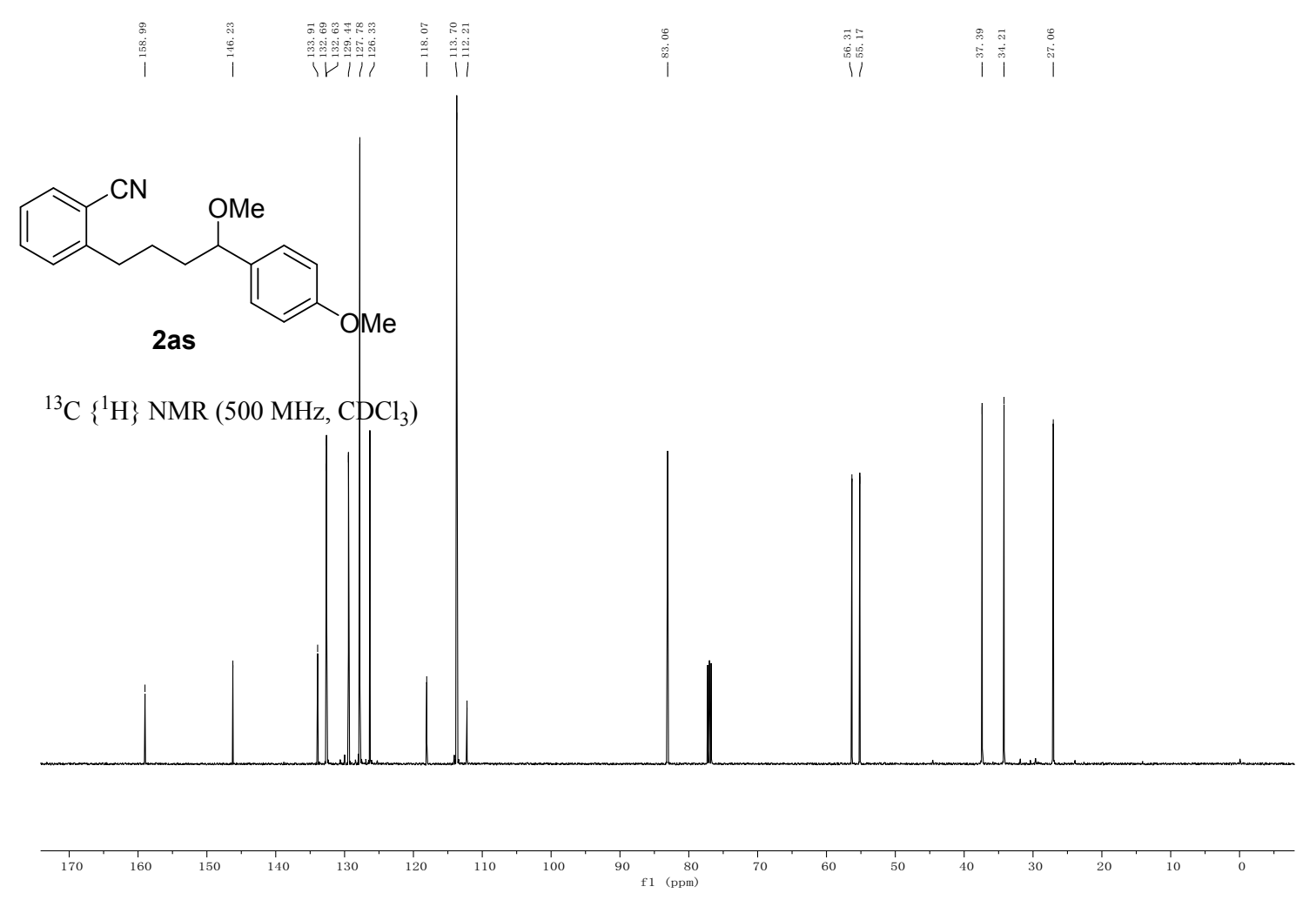

1
0<smiles>C1CCC2CCCCC2C1</smiles><smiles>C1CCCCC1</smiles><smiles>CCC1CCCCC1</smiles><smiles>COc1ccc(C(CCCCCCC#N)OC)cc1</smiles>

2at

${ }^{1} \mathrm{H}$ NMR (500 MHz, $\mathrm{CDCl}_{3}$ )

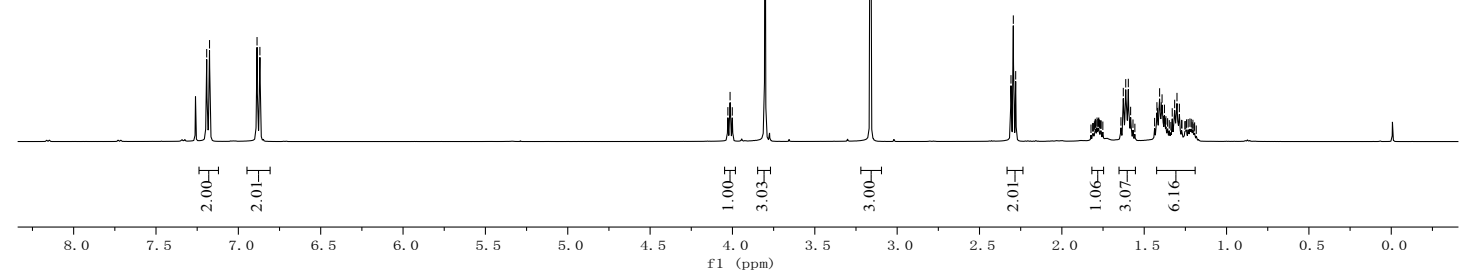


<smiles>COc1ccc(C(CCCCCCC#N)OC)cc1</smiles>

2at
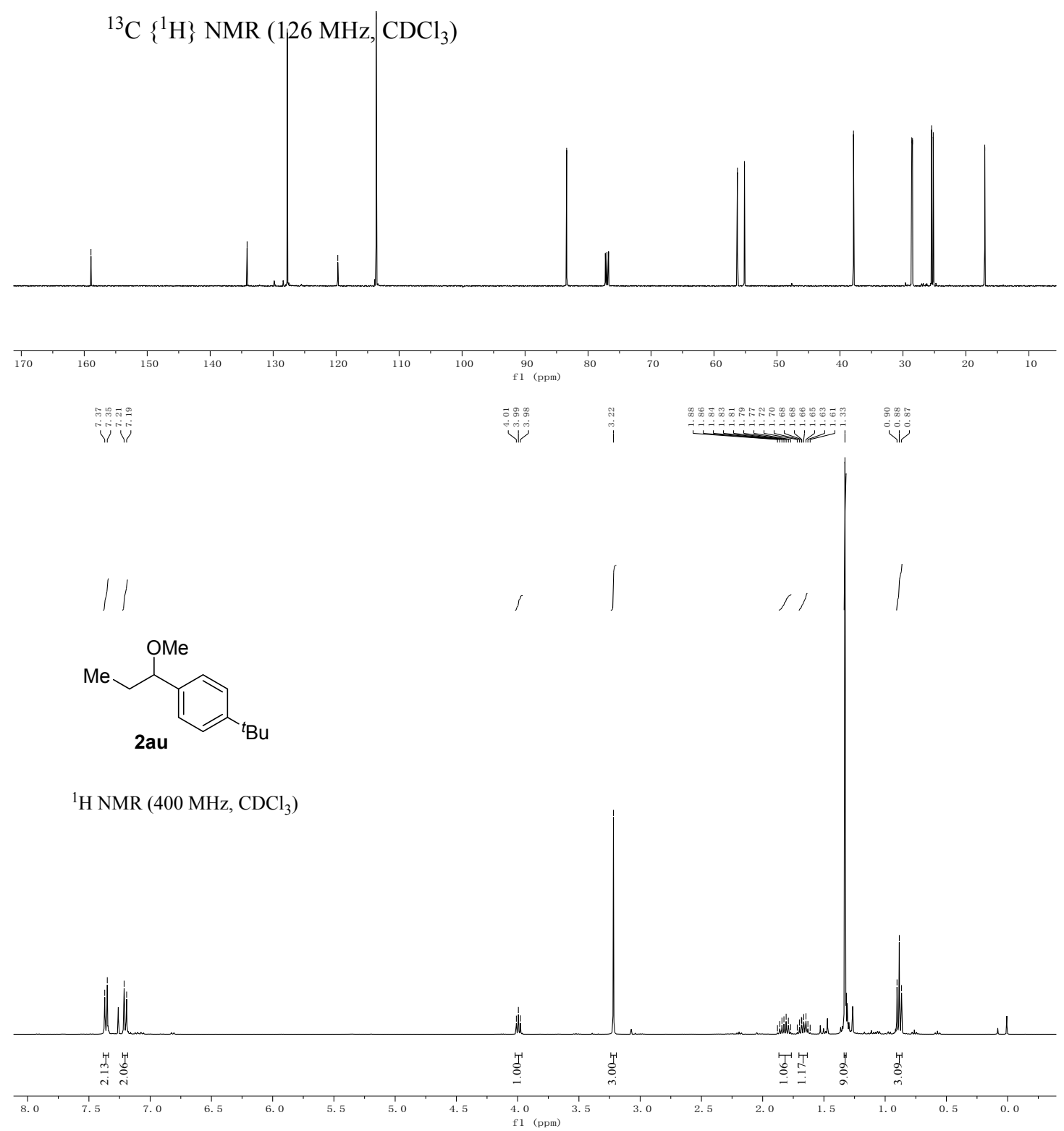


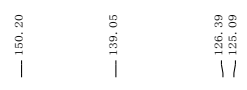

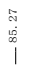

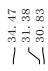

$\stackrel{8}{\circ}$

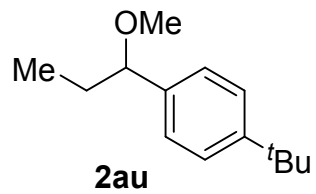

${ }^{13} \mathrm{C}\left\{{ }^{1} \mathrm{H}\right\}$ NMR $\left(100 \mathrm{MHz}, \mathrm{CDCl}_{3}\right)$
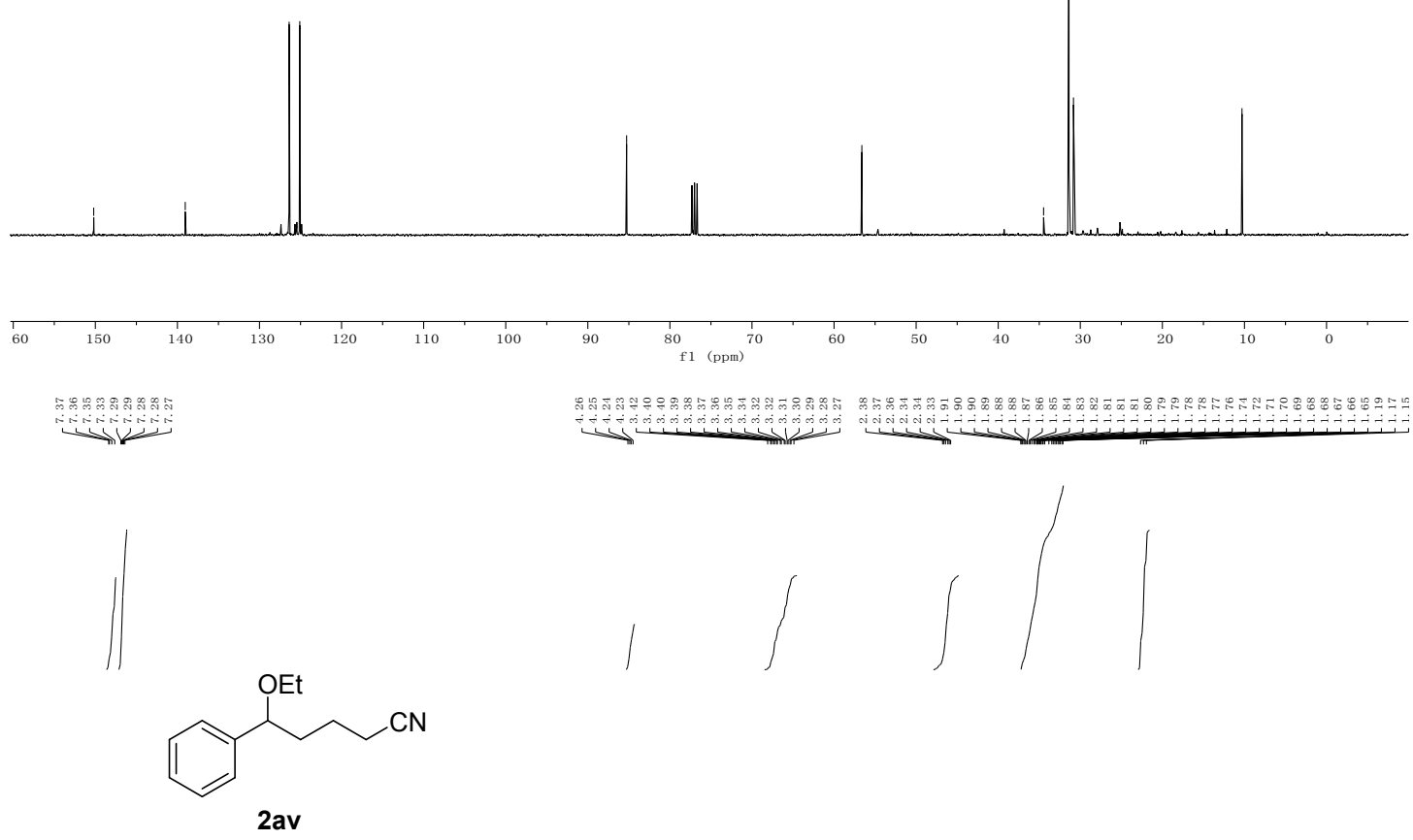

${ }^{1} \mathrm{H}$ NMR (400 MHz, $\mathrm{CDCl}_{3}$ )

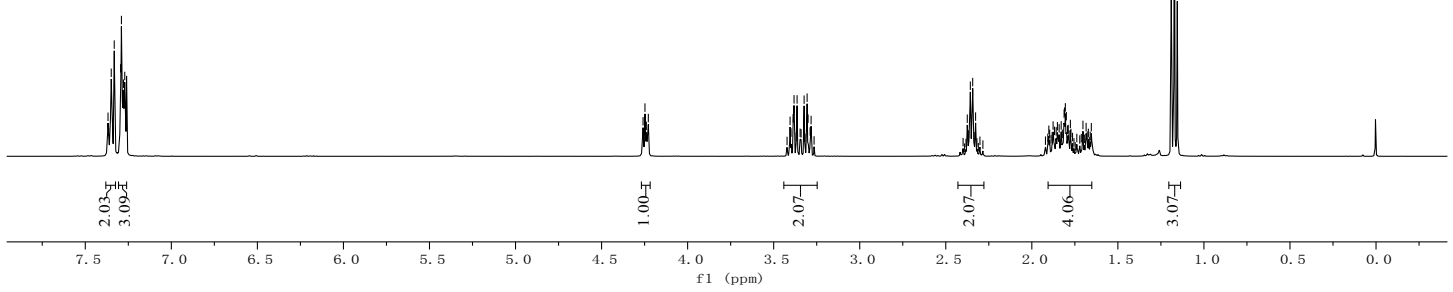

S28 


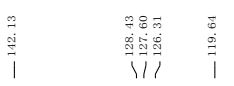<smiles>CCOC(CCCC#N)c1ccccc1</smiles>

2av

${ }^{13} \mathrm{C}\left\{{ }^{1} \mathrm{H}\right\}$ NMR $\left(100 \mathrm{MHz}, \mathrm{CDCl}_{3}\right)$
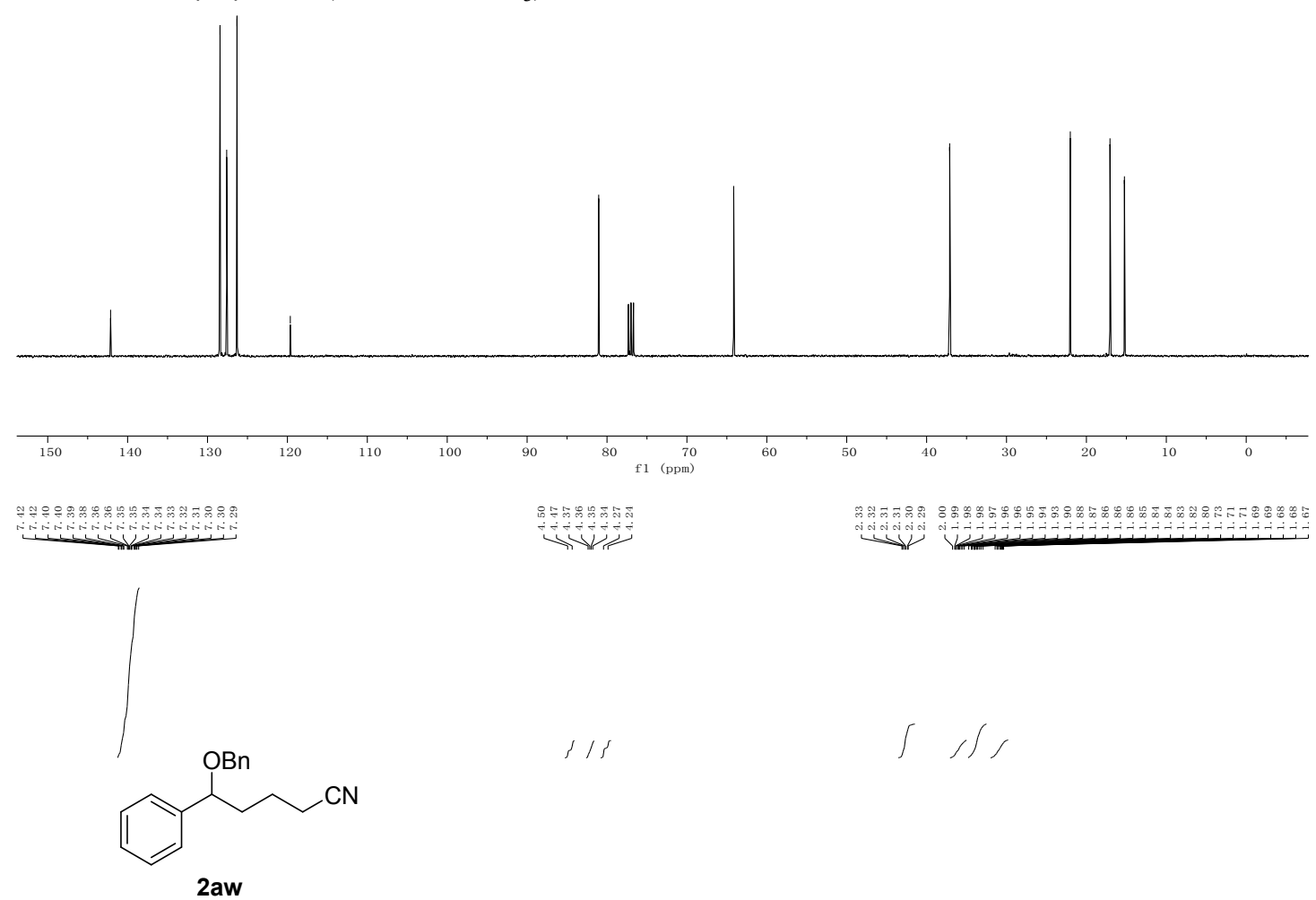

${ }^{1} \mathrm{H}$ NMR $\left(400 \mathrm{MHz}, \mathrm{CDCl}_{3}\right)$

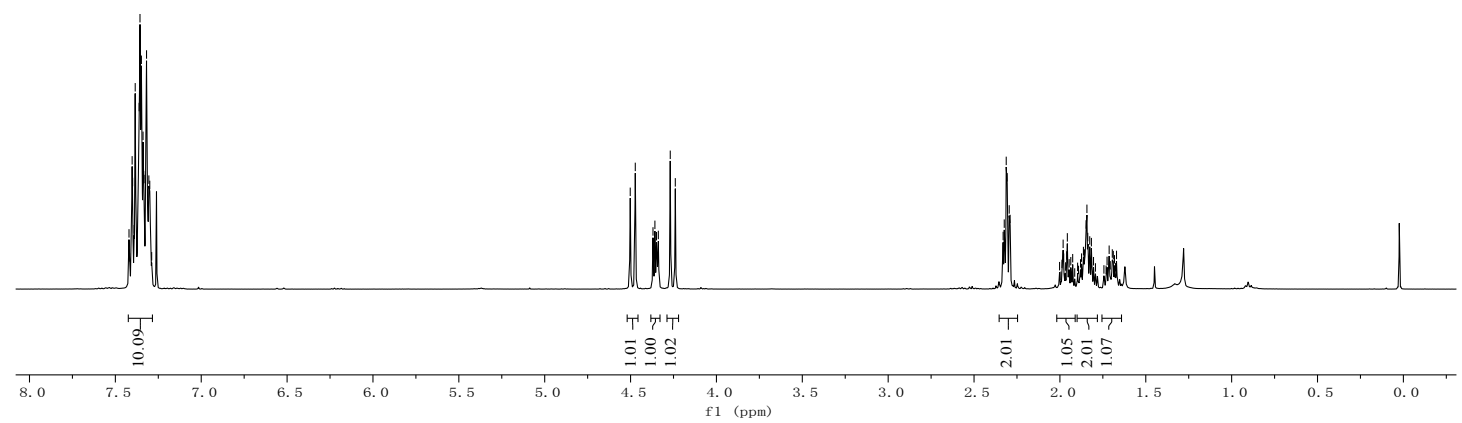




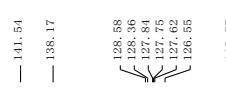

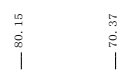

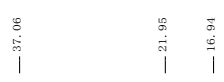
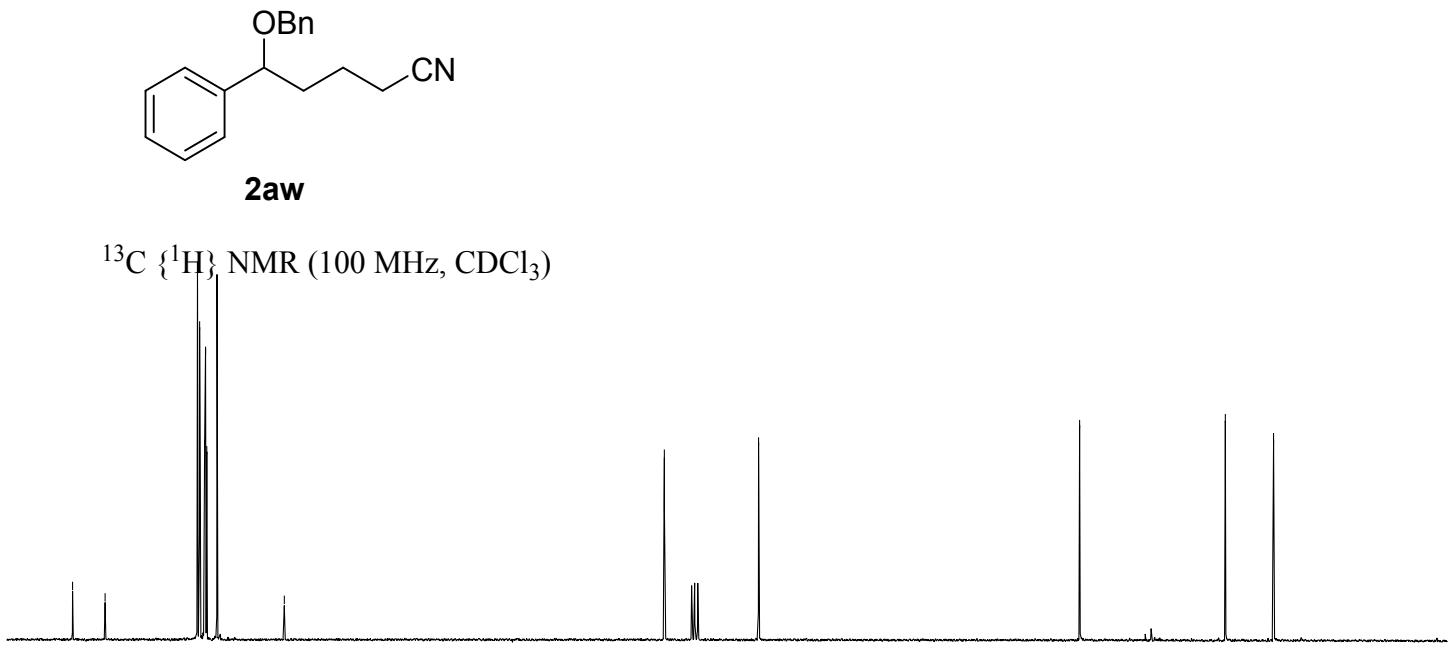

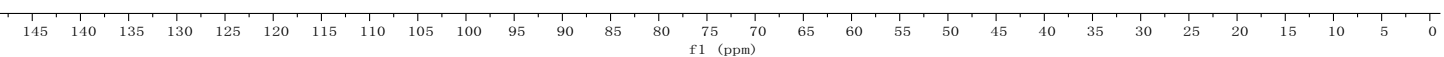
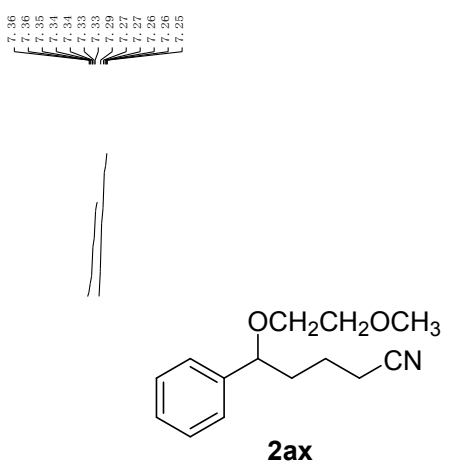

${ }^{1} \mathrm{H}$ NMR $\left(400 \mathrm{MHz}, \mathrm{CDCl}_{3}\right)$

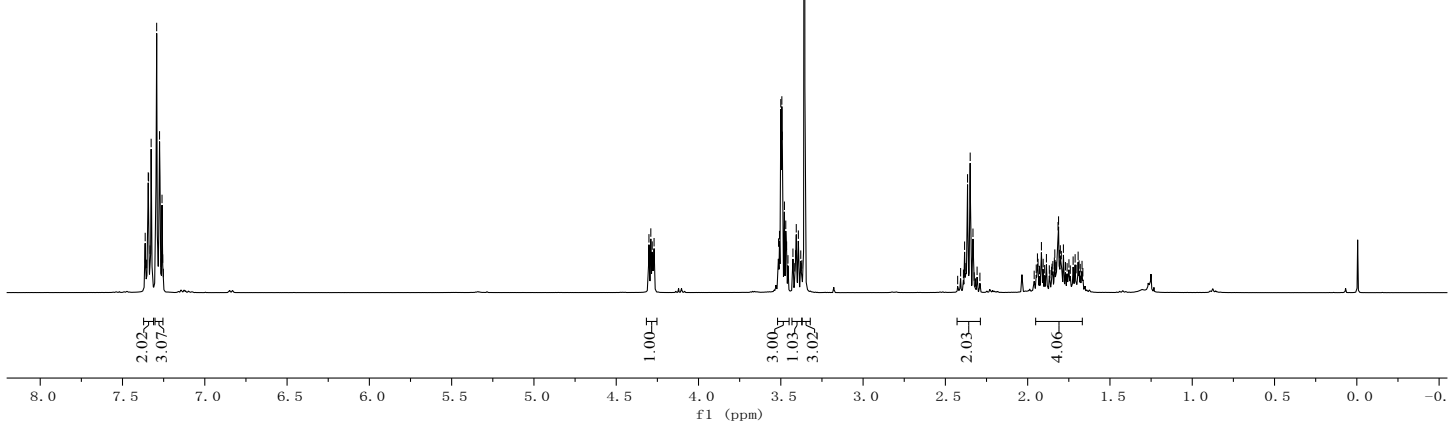

S30 


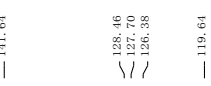

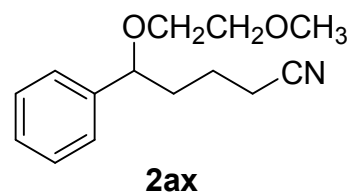

${ }^{13} \mathrm{C}\left\{{ }^{1} \mathrm{H}\right\}$ NMR $\left(100 \mathrm{MHz}, \mathrm{CDCl}_{3}\right)$
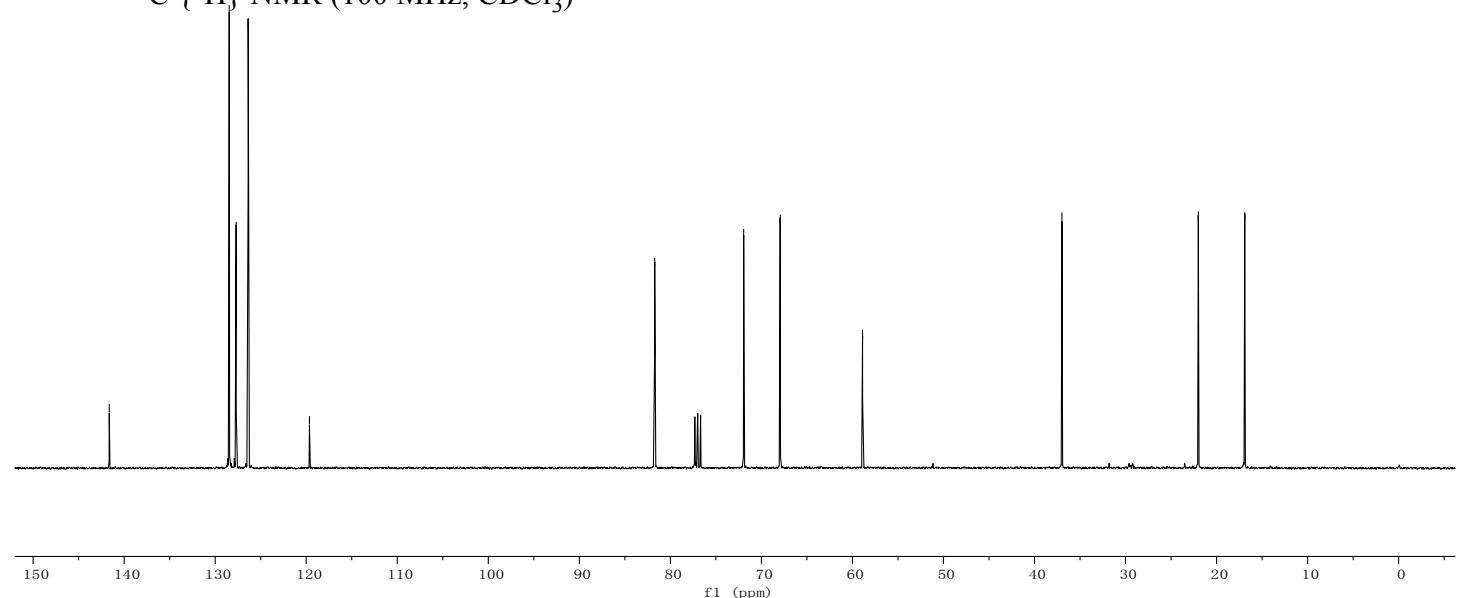

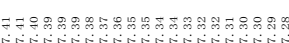

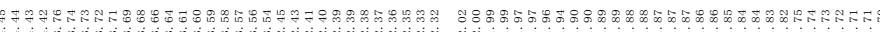

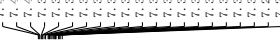

4 U1

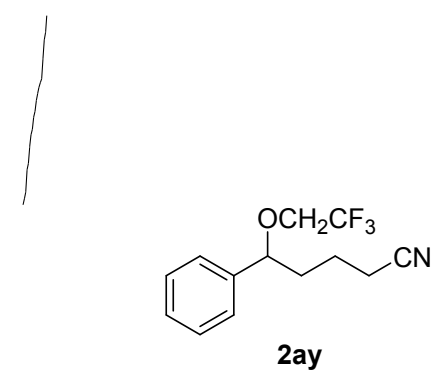

${ }^{1} \mathrm{H}$ NMR (400 MHz, $\mathrm{CDCl}_{3}$ )

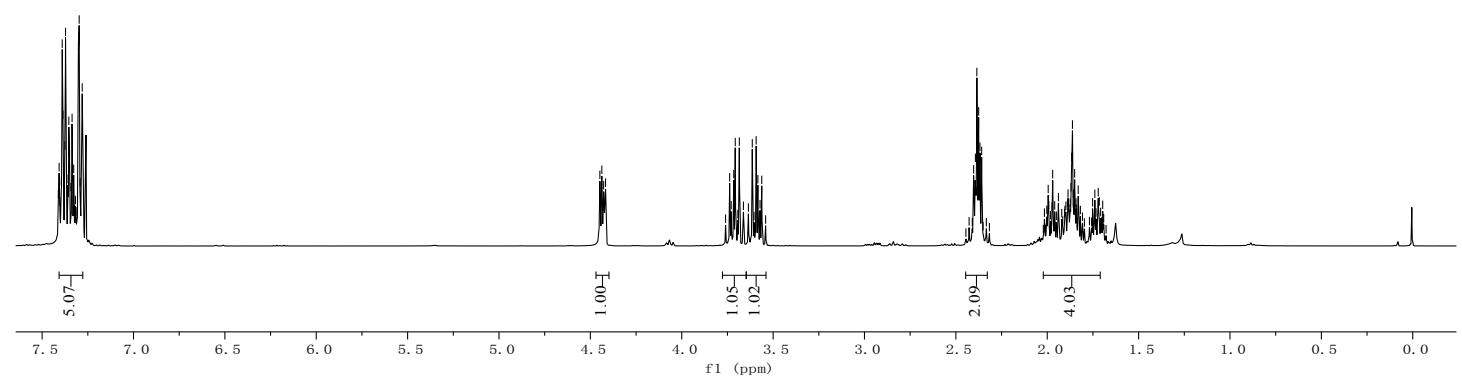




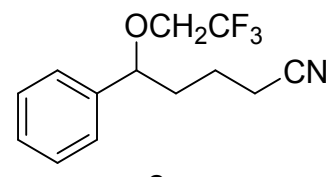

2ay
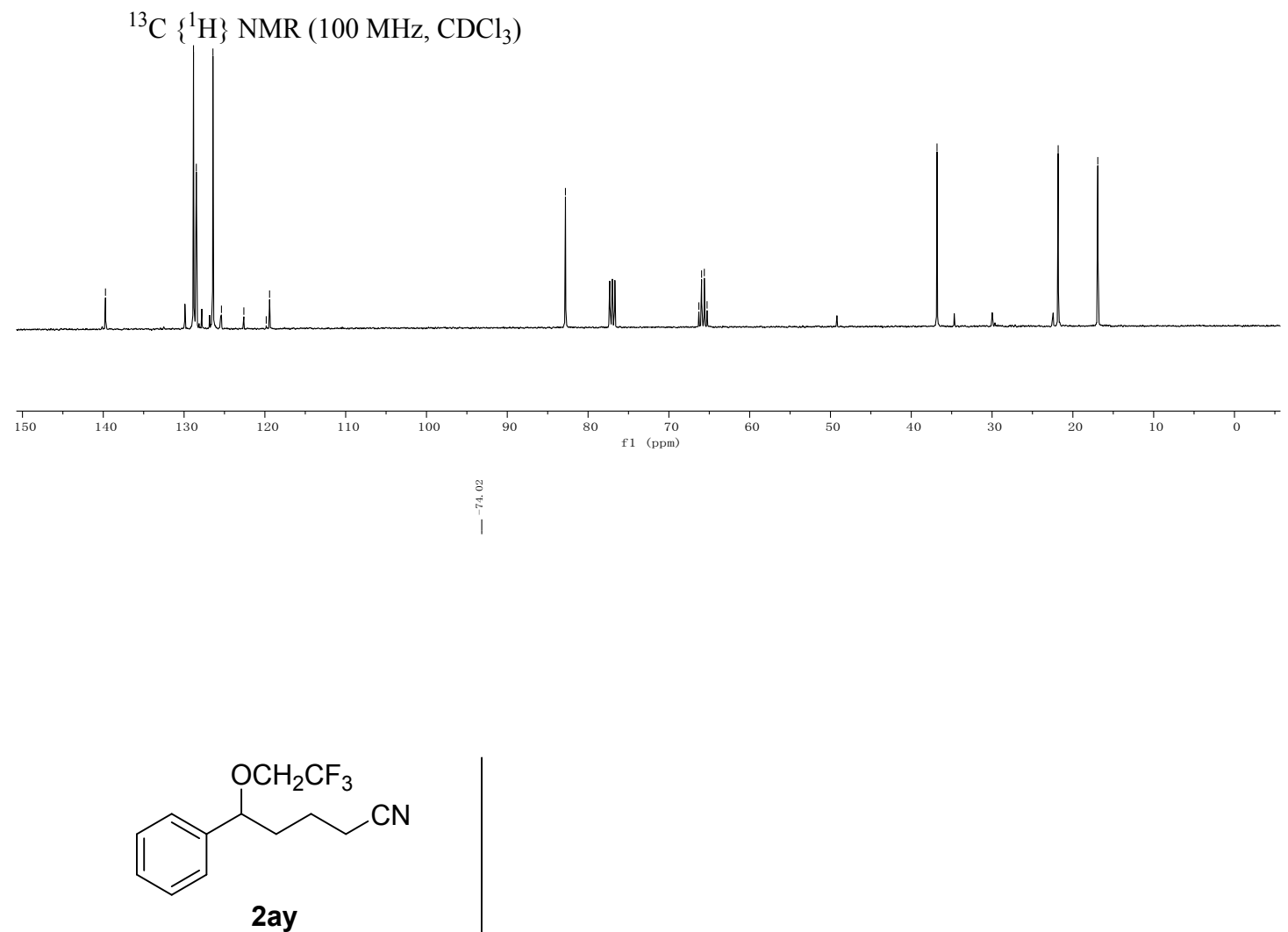

${ }^{19} \mathrm{~F}\left\{{ }^{1} \mathrm{H}\right\}$ NMR $\left(376 \mathrm{MHz}, \mathrm{CDC}{ }_{3}\right)$ 


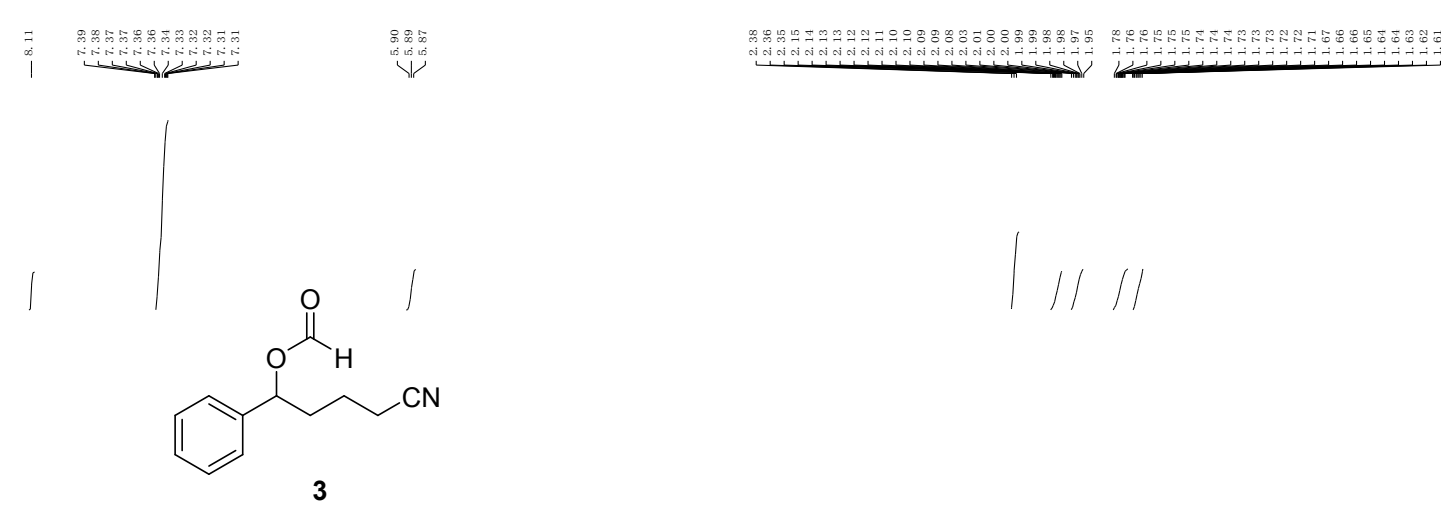

${ }^{1} \mathrm{H}$ NMR (500 MHz, $\mathrm{CDCl}_{3}$ )
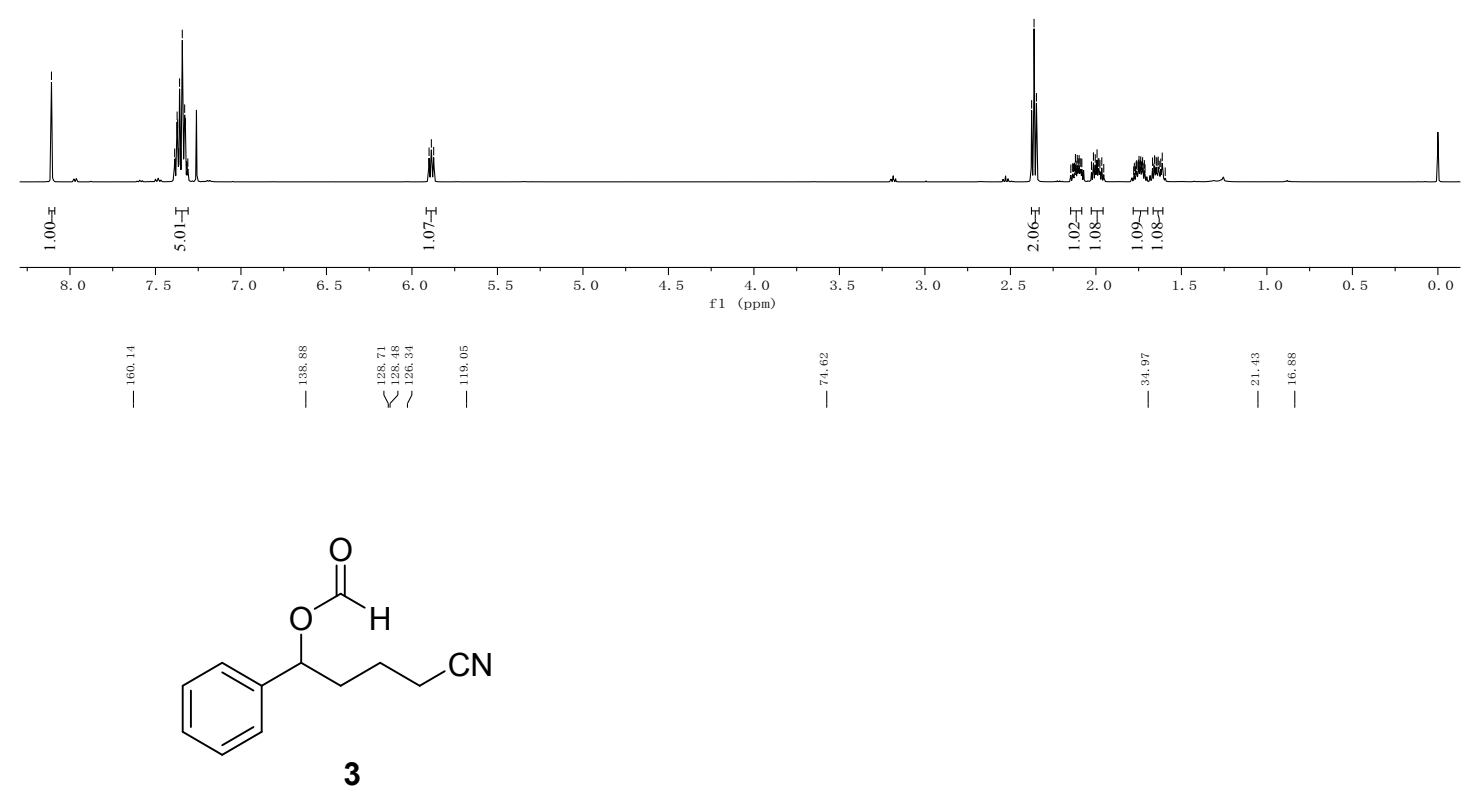

${ }^{13} \mathrm{C}\left\{{ }^{1} \mathrm{H}\right\}$ NMR $\left(126 \mathrm{MHz}, \mathrm{CDCl}_{3}\right)$
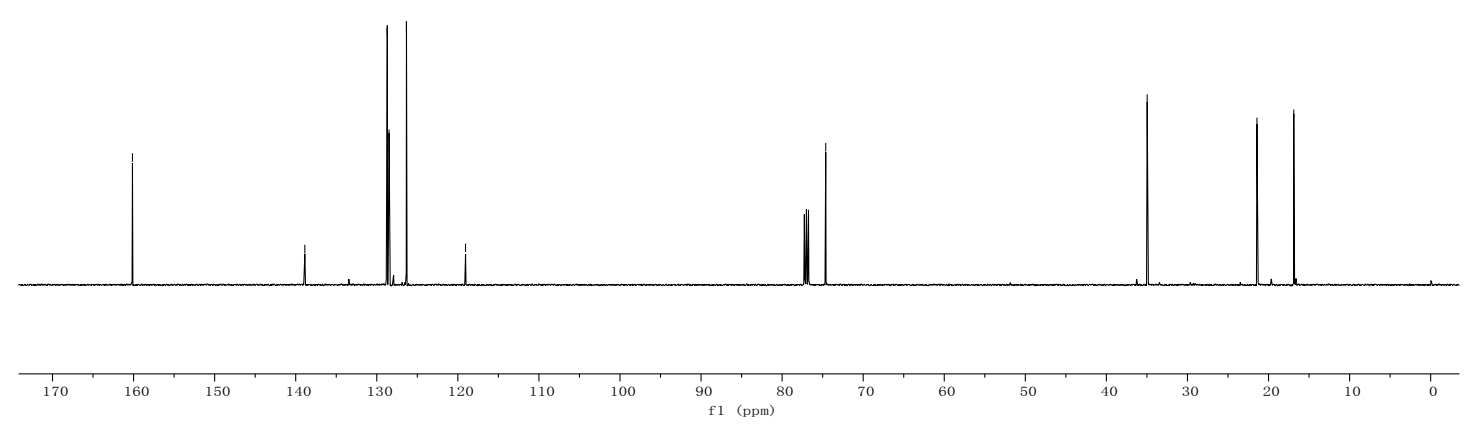


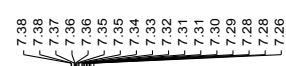

1
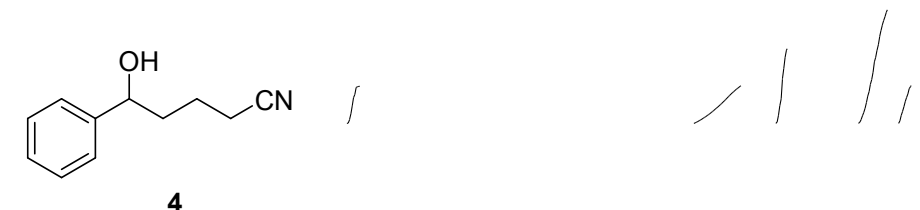

${ }^{1} \mathrm{H}$ NMR $\left(400 \mathrm{MHz}, \mathrm{CDCl}_{3}\right)$
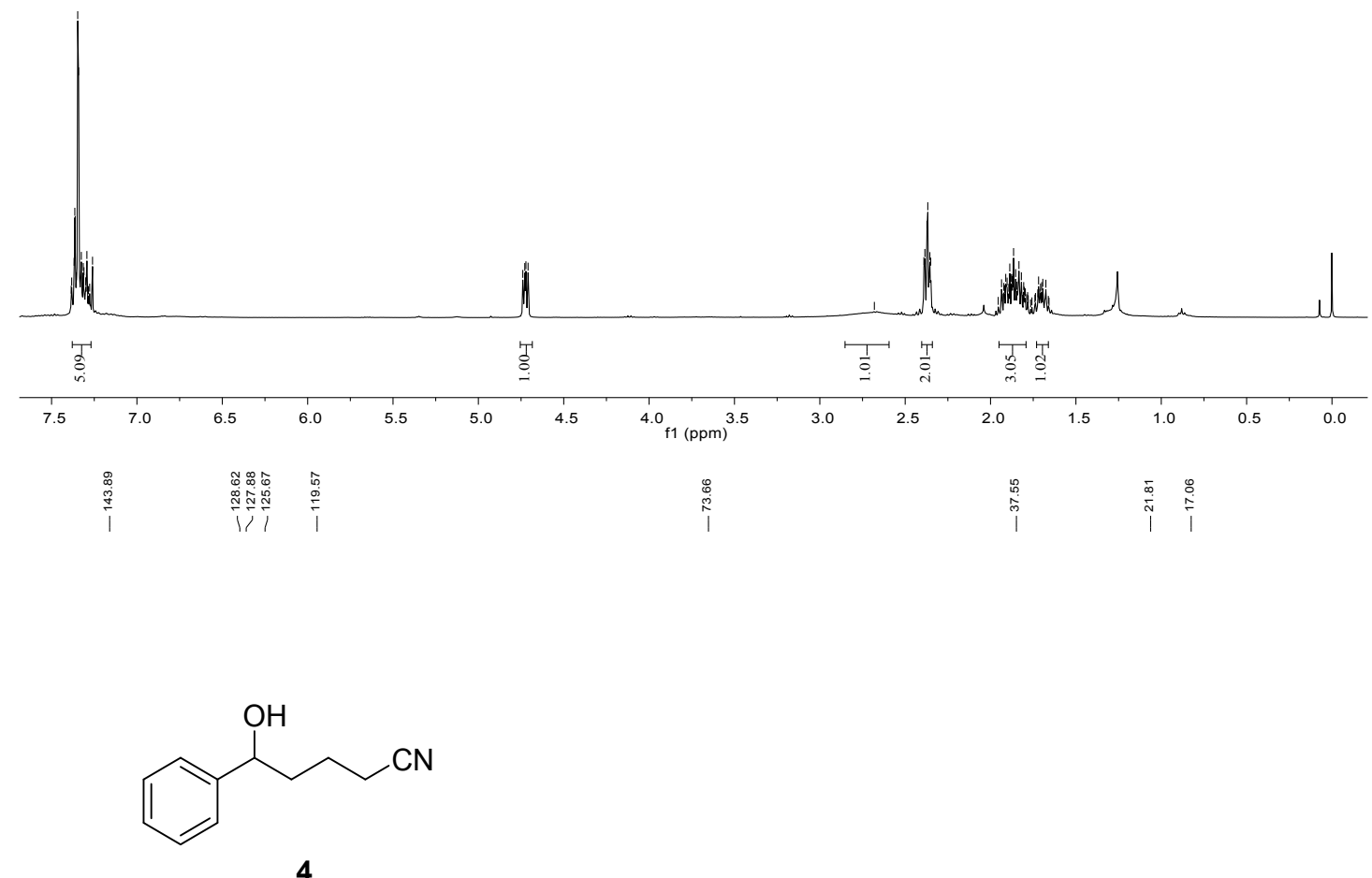

${ }^{13} \mathrm{C}\left\{{ }^{1} \mathrm{H}\right\} \mathrm{NMR}\left(126 \mathrm{MHz}, \mathrm{CDCl}_{3}\right)$

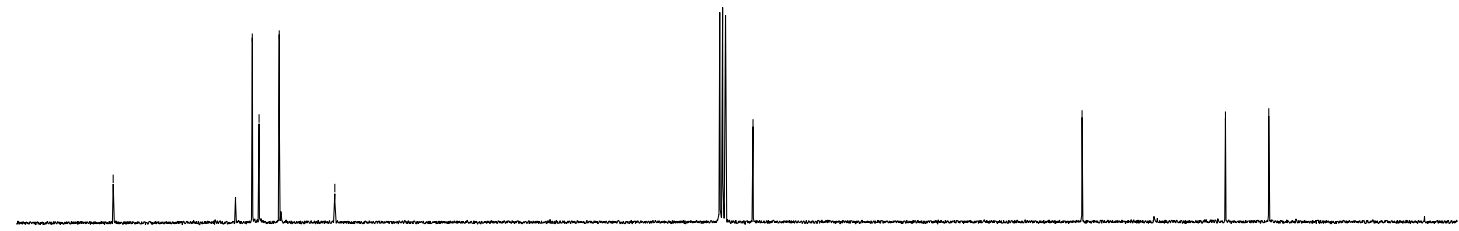

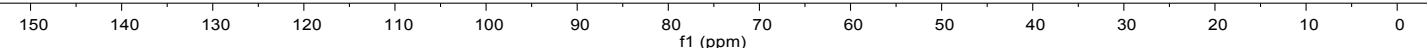



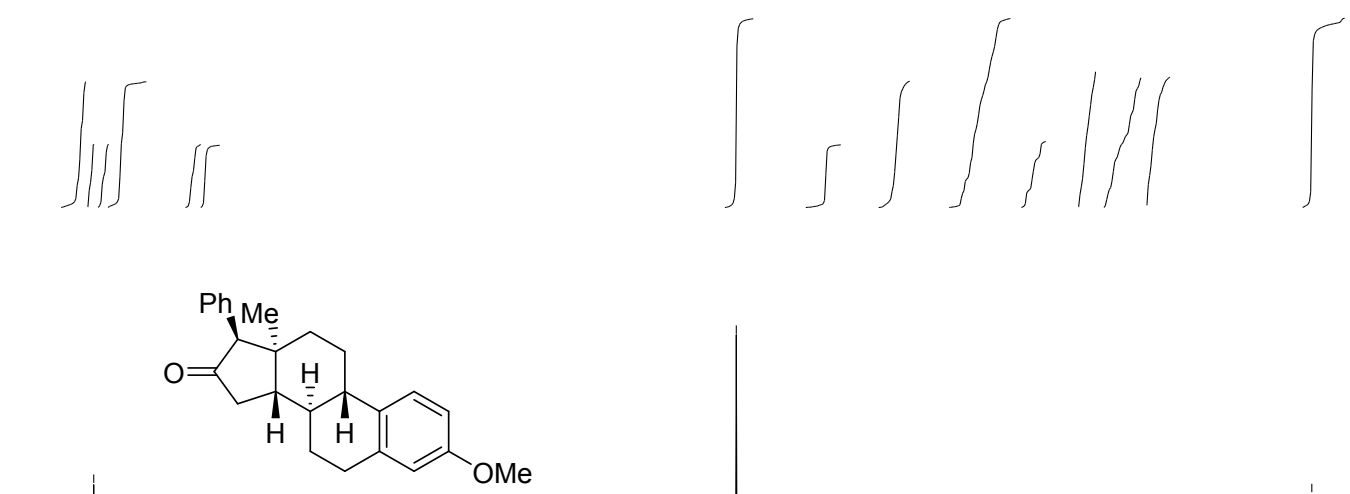

3b

${ }^{1} \mathrm{H}$ NMR $\left(400 \mathrm{MHz}, \mathrm{CDCl}_{3}\right)$

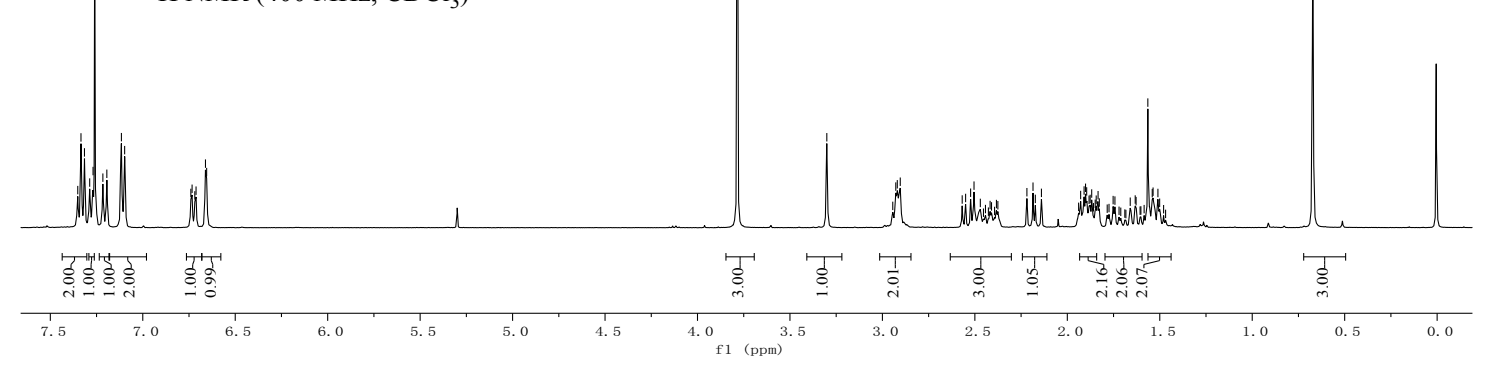

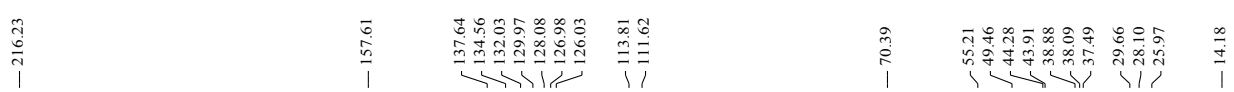

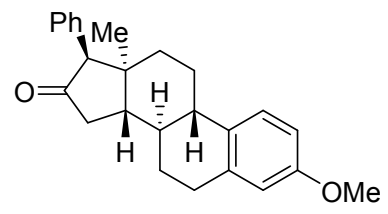

3b

${ }^{13} \mathrm{C}\left\{{ }^{1} \mathrm{H}\right\}$ NMR $\left(100 \mathrm{MHz}, \mathrm{CDCl}_{3}\right)$

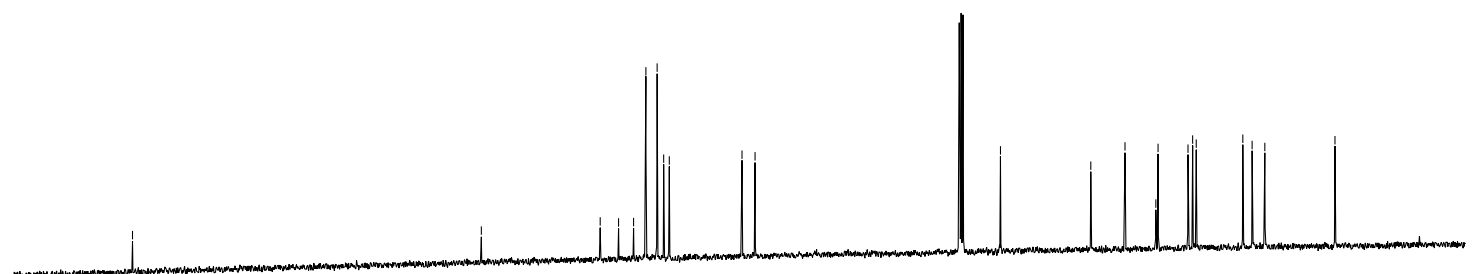




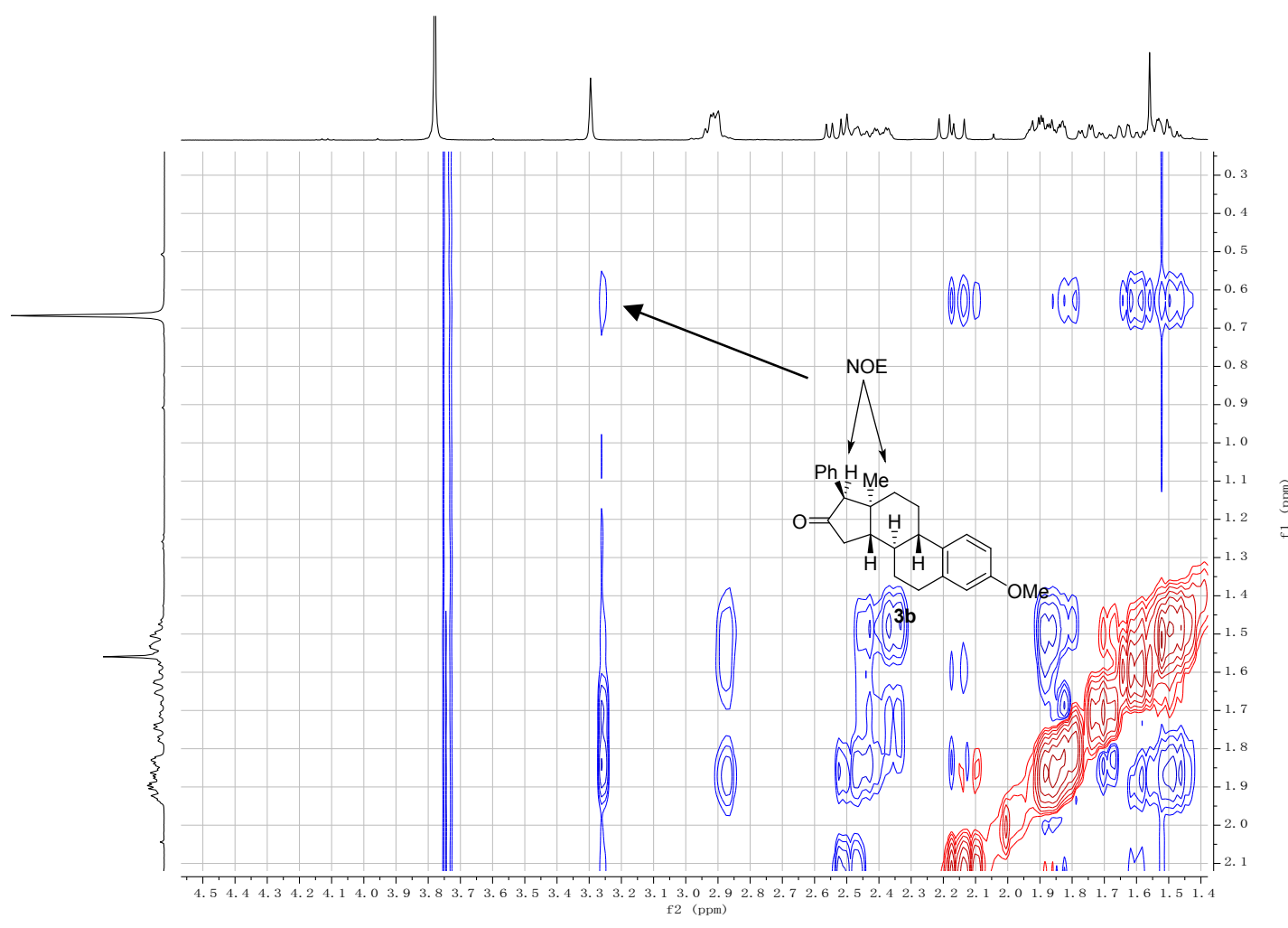

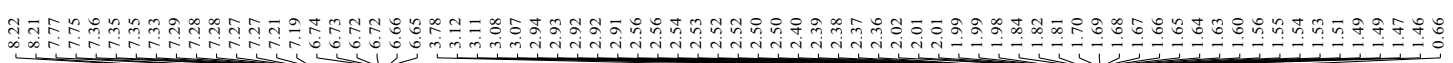
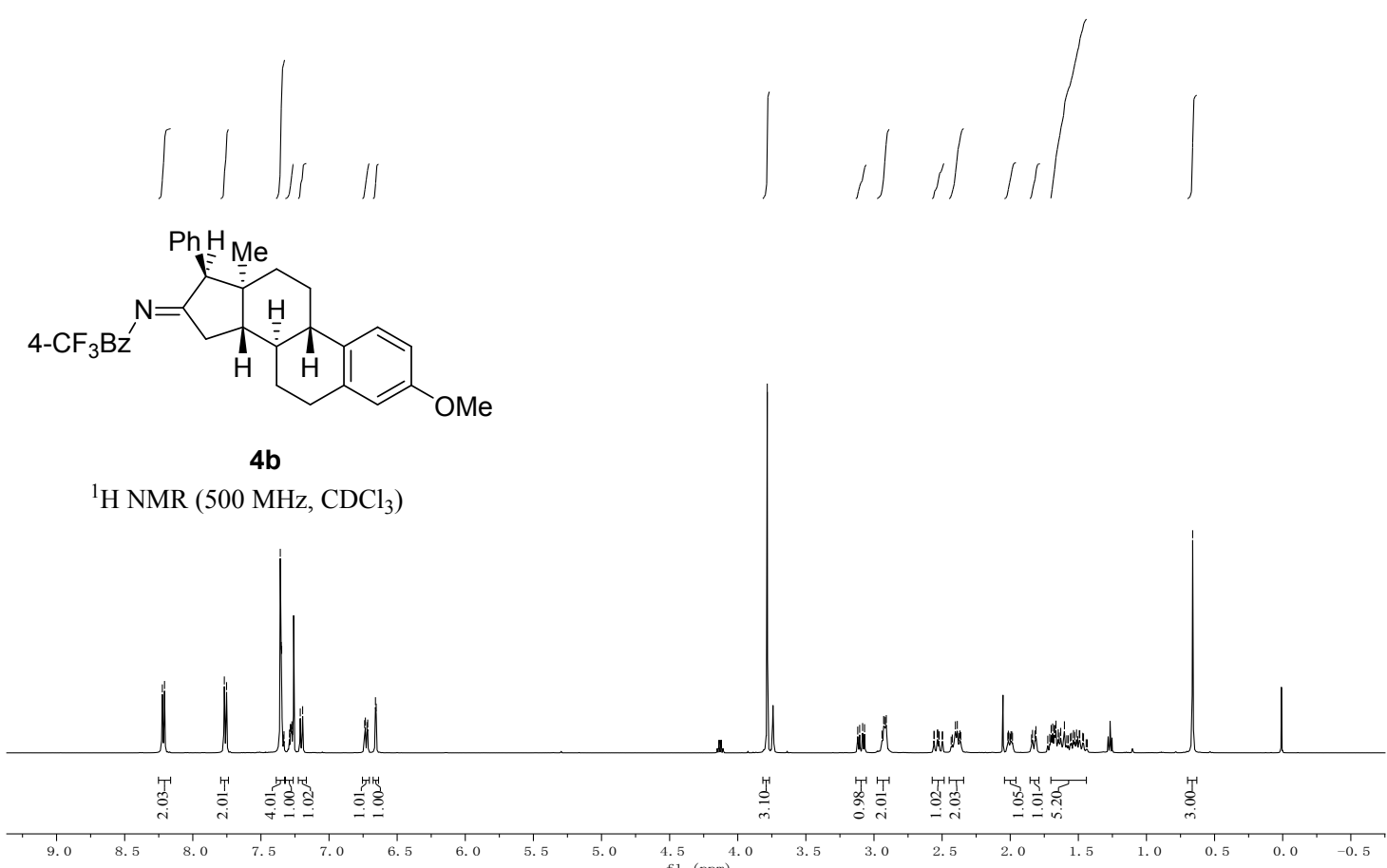

S36 


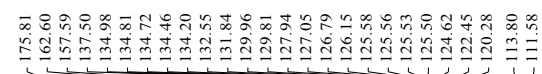

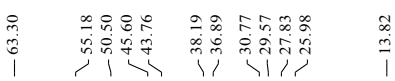

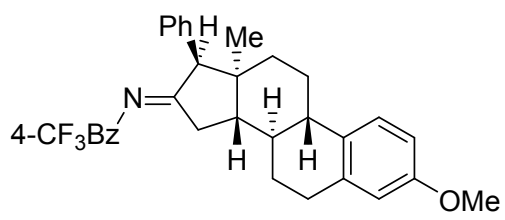

4b

${ }^{13} \mathrm{C}\left\{{ }^{1} \mathrm{H}\right\}$ NMR $\left(126 \mathrm{MHz}, \mathrm{CDCl}_{3}\right)$
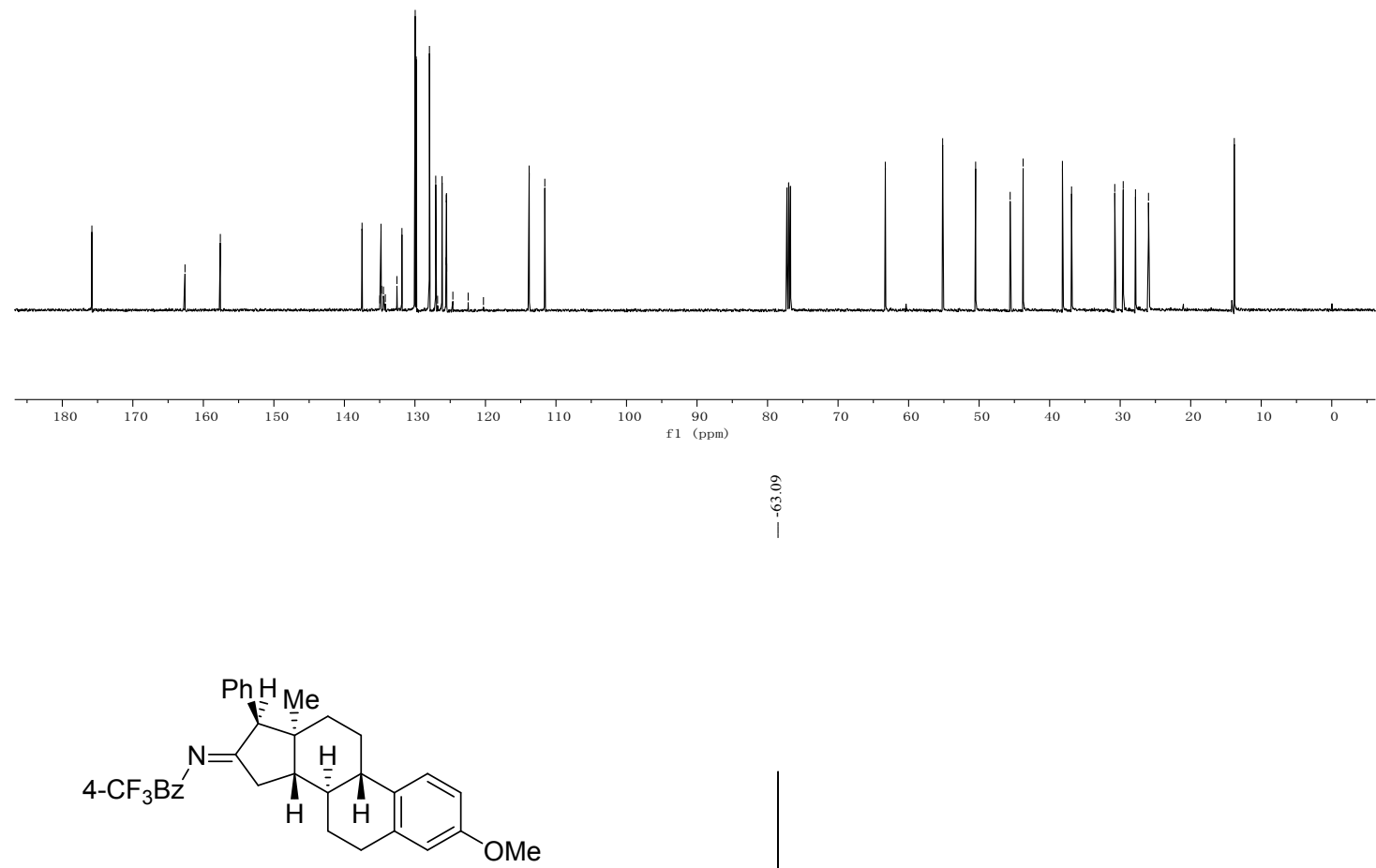

4b

${ }^{19} \mathrm{~F}\left\{{ }^{1} \mathrm{H}\right\}$ NMR $\left(471 \mathrm{MHz}, \mathrm{CDCl}_{3}\right)$ 

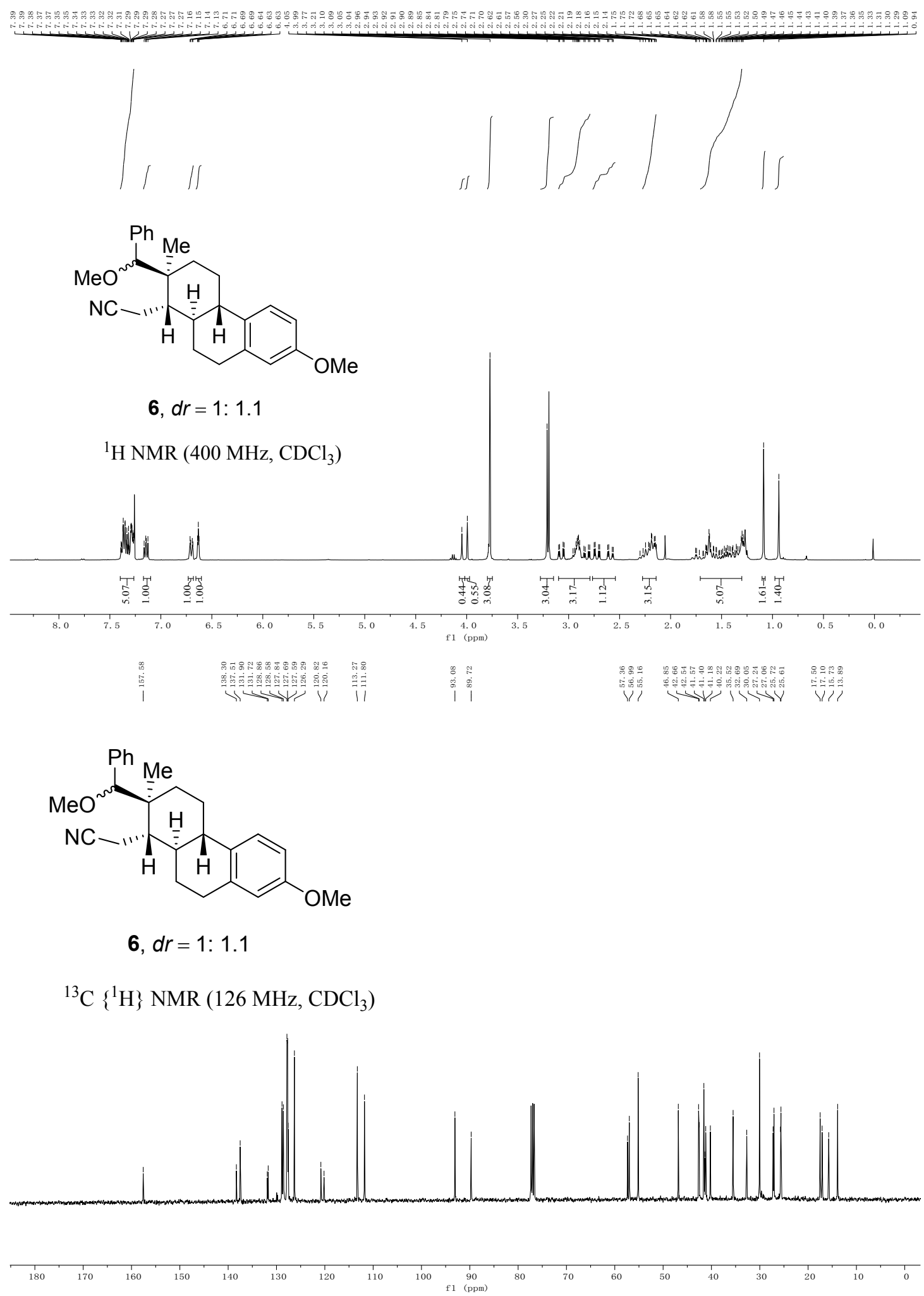